\title{
Modelling and Control of Multi-Energy Systems through Multi-Prosumer Node and Economic Model Predictive Control
}

\author{
Pierre Clément Blaud ${ }^{\mathrm{a}, \mathrm{c}}$, Pierrick Haurant ${ }^{\mathrm{b}}$, Fabien Claveau $^{\mathrm{c}}$, Bruno \\ Lacarrière $^{\mathrm{b}}$, Philippe Chevrel ${ }^{\mathrm{c}}$, Anthony Mouraud ${ }^{\mathrm{a}}$ \\ ${ }^{a}$ CEA, DRT, CTREG, DGDO, technocampus Océan, 5 Rue de l'Halbrane, F-44340 \\ Bouguenais, France \\ ${ }^{b} I M T$ Atlantique, GEPEA, UMR CNRS 6144, F-44307 Nantes, France \\ ${ }^{c} I M T$ Atlantique, LS2N, UMR CNRS 6004, F-44307 Nantes, France
}

\begin{abstract}
The present study deals with Multi-Energy Systems (MES) modelling and advanced control with Economic Model Predictive Control (EMPC). MES provide energy flexibility, efficiency, and adaptability thanks to several energy carriers. MES are identified as a lever for integrating renewable energy. A MES novel formulation technique called Multi-Prosumer Node (MPN) is developed in this paper. MPN makes possible the modeling of MES, considering MES dynamics, several energy carriers, converters, on-grid, and off-grid. In addition, this MES modeling approach is compatible with predictive control strategies like the EMPC. In fact, EMPC is able to take into account loads, weather, renewable power and energy grid cost predictions to minimise economic costs. A real case study is implemented to examine MPN capabilities, which it is composed of renewable generators, loads, storages from two-energy carriers. Two real scenarios have been developed in order to represent realistic winter and summer cases. Simulation results, thanks to modelling with MPN and EMPC advanced control, demonstrate that the node is optimally controlled, devices dynamics are considered on a minute scale, and energy conversion from one carrier to another one is taken into account while economic cost minimisation is performed. The gained results indicate that the presented MPN modelling and optimisation approach reduces economic cost by $8.21 \%$ in winter case and $84.24 \%$ in summer case compared to the benchmarks which are composed of rule-based control.
\end{abstract}

Keywords: Multi-Energy System, Economic Model Predictive Control, Multi-Prosumer Node, Energy Hub

Email address: pierre.blaud@cea.fr (Pierre Clément Blaud) 


\section{Introduction}

Control and systems technologies in the energy sector are confronted with great challenges in order to increase the share of renewable energy, optimise energy harvesting, integrate intermittent renewable sources and use energy resources wherever and whenever it is available [1]. Some of these challenges can be addressed by Multi-Energy Systems (MES). MES is a framework which couples different energy carriers. These couplings increase the flexibility of the energy system and improves its efficiency by using energy carriers synergies. Finally, MES are adapted to local and small-scale energy production and consumption [2]. At the same time, wind turbines and solar power plants are spread over a territory. Their intermittent production is a limit to their integration to the local network. Their development is facing challenges to sustain the reliability of the network and ensure the balance between demand and supply. These challenges can be tackled by optimisation and control technologies [1].

In [3], the authors use optimisation techniques to control various energy systems like power plants, wind turbines, supermarket refrigeration systems, heat pump, residential heating and electric vehicles' battery. Additionally, in [4] the control of a micro-grid community is done by a system composed of photovoltaic panels, fuel cells and an electric storage. In another survey, an electric system composed of photovoltaic panels, electric storage, electric vehicles, controllable and non-controllable loads, is optimised [5]. MES made up of smart manufacture of an olive mill is controlled in [6]. In this work,carriers which composed the latter system were electricity, natural gas while the energy resources were wind, biomass and sun.

A lot of optimisation techniques have been applied to renewable energies [7] and MES [8], such as linear programming [9], nonlinear programming [10], integer programming [11], heuristic [12], meta-heuristic [13], distributed computing [14], robust optimisation [15] and multi-objective optimisation [16]. Indeed, the cost function of optimisation process needs to be minimised [8, 7]. Also, some extra information can be added to the cost function. For instance, an optimisation of a cost function over a horizon to follow the economic optimum, system dynamic, multi-inputs and multi-outputs systems, constraints from actuators, disturbances and predictions to follow the optimum trajectory are taken into account $[17,18,19]$.

Some optimisation techniques are model-free and systems can be considered as black boxes [20]. Some other optimisation techniques are model-based optimisation methods and a physical representation of the system is required [10]. Some papers deal with physical representation as state-space in order to control the system with an optimisation [21]. Two main energy state-space model concepts have been identified in literature for the energy systems control, namely the Prosumer Node (PN) [4, 22, 23] and the Energy Hub (EH) [14, 6, 21, 24, 25].

Prosumer is a portmanteau word between producer and consumer $[5,26,27]$. Prosumer node is an energy system concept where producer and consumer are linked to each other within a node. Prosumer node control can be seen in [4, $5,22,23]$. The aim is to minimise the operation cost whilst maximising self- 
consumption and selling excess of energy from a micro-grid. Moreover, statespace model and power balance of the prosumer node are visible in $[4,22,23]$. The main advantages of the prosumer node should be mentioned as state-space model, power balance, and performing optimisation process in order to complete economic optimisation. In addition, disturbances can be taken into account, and bidirectional electric power flow is modelled in prosumer node strategy [4, 22, 23]. However, some drawbacks still remain because prosumer node deals only with electricity vector $[4,5,22,23]$. By the authors' best knowledge,there are few papers which deal with prosumer node concept and MES [28], likewise, a state-space model and power balance which can be taken into consideration by the optimisation problem is still not displayed. Moreover in literature, an applied state-space model for electrical systems has not still been extended to a MES.

EH concept was proposed in order to consider multi-energy carriers with converters, conditioners and storage systems [29]. It has been employed in optimal power flow with MES $[8,30]$. EH optimisation with a state-space model has been proposed in literature $[6,14,21,24]$. The main advantages of $\mathrm{EH}$ state-space model may be mentioned as following: the state-space model can be used for the optimisation process in order to complete economic optimisation, grid exchange and controllable equipment are modelled in distinct carrier representation. However, some drawbacks are noticeable like charging and discharging storage are shown with a double matrix formulation (one for charging and second one for discharging), primary energies are used, and renewable energy systems are formulated only with a conversion factor. This conversion factor from primary energies causes ratio to the central energy optimisation problem. Renewable energy systems have their own optimisation process with the purpose of maximising the harvested energy. For instance, in photovoltaic systems this controller is called maximum point tracking. From a point of view of a central controller with the purpose of dispatching energy and increasing carrier synergies, the ratio from primary energy to power adds computational issues. Conversion efficiency is expressed as steady state and therefore hourly optimisation is done [6]. It is obvious that hourly optimisation process brings lack of precision with long-time thermal dynamics.

Studies on both prosumer node and EH have shown some lacks among existing modelling techniques applied for optimisation. Proper modelling of prosumer and of conversion are currently missing for MES. Besides, EH modelling uses a steady state conversion factor, implementing constant value or leading to computational issues for variable factors. The contribution of the present work is to introduce the concept of Multi-Prosumer Node (MPN) that combines the following features:

- MPN is able to model a MES to be used for optimisation in the case of multiple carriers;

- Energy coupling from a carrier to another is not represented with constant conversion factors: it relies on conversion models; 
- Systems dynamics are taken into account. Consequently, MPN is also suitable for optimisation considering short time horizon;

- A methodology is presented to build the MPN from MES's analysis, since then controlling the MES through optimisation using MES model is achievable by the method.

\section{Multi-Prosumer Node Model}

The flowchart in figure 1 summarizes the methodology proposed to form a MES controller. It has three main steps, MES classification, MPN modelling and EMPC tuning. These steps are detailed along with sections 2 and 3.

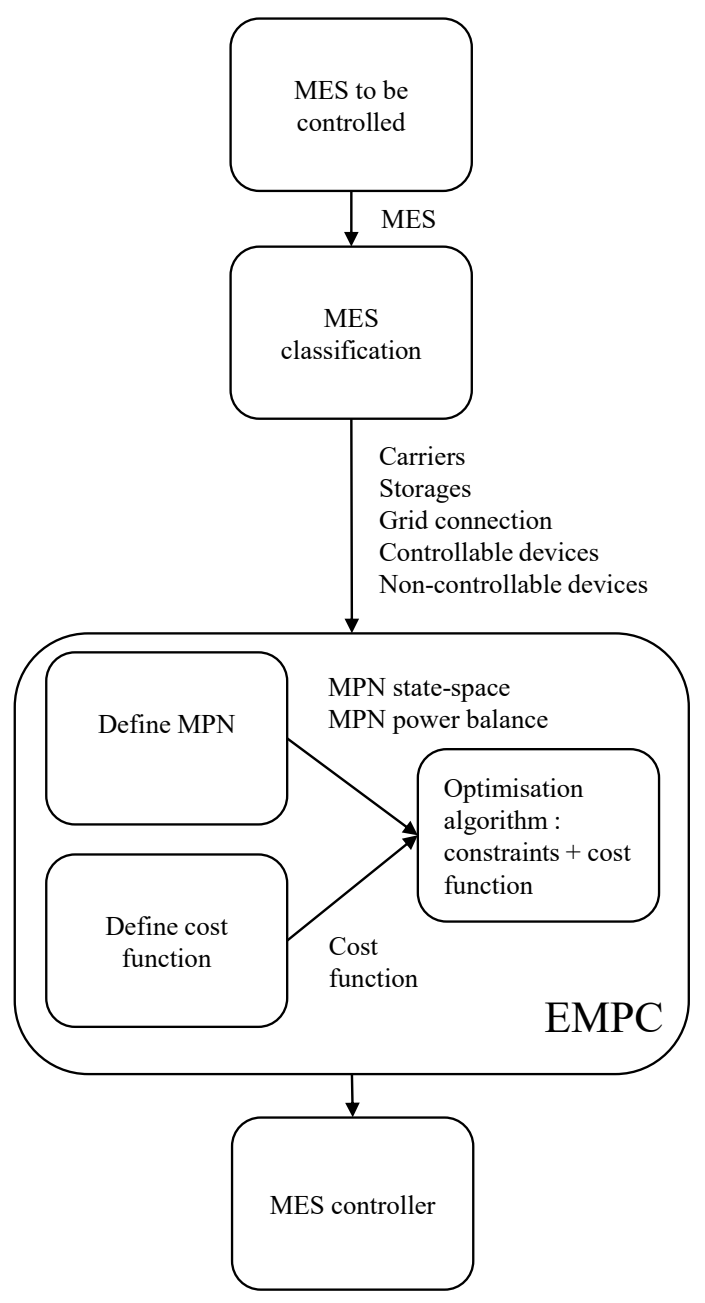

Figure 1: Designed and applied methodology in the present study. 


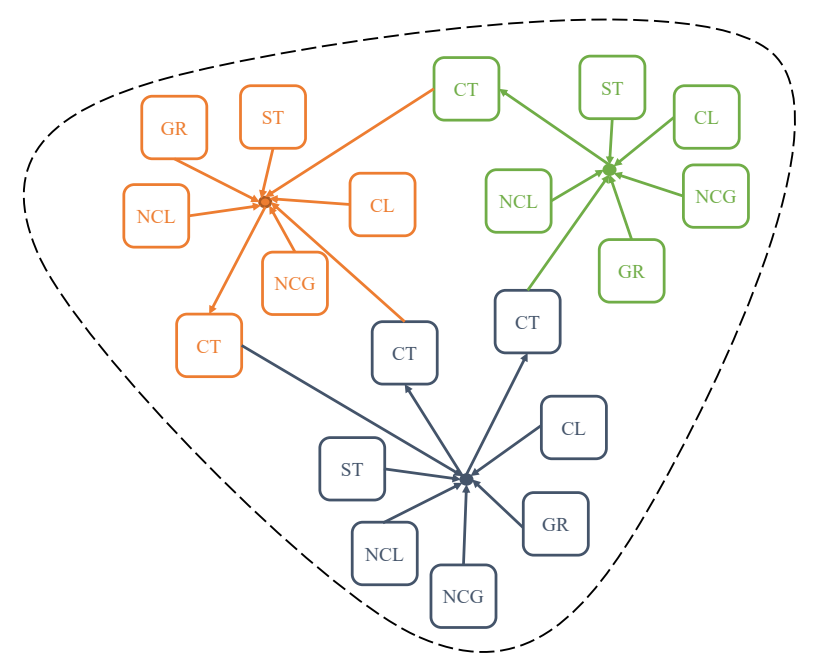

Figure 2: Node power flows of possible devices formed at the MES with three energy carriers. CL: controllable loads, CT: ConverTers, GR: GRids, NCG: Non-Controllable Generator, NCL: Non-Controllable Loads, ST: storages. Colour represents different energy carriers.

Equipment that compose MES are energy systems, such as storage, energy carriers, converters from one energy carrier to other(s) energy carrier(s), renewable energy generators, controllable and non-controllable loads. All energy systems are categorised in two distinct groups. The first group includes devices with controllability feature like storages, converters, grid exchanges and controllable loads. (Please note that controllable here means that a control action can be carried out.) The second group contains devices without controllability capabilities, like non-controllable loads and renewable energy sources such as solar panels.

The power flow exchange from an energy carrier to devices can be seen in figure 2. In this research, we focused on power balanced approach. MPN model formulation includes two components, the first one is the state-space model and the second one is the power balance. MPN state-space model and MPN power balance flowcharts are shown in figures 3 and 4 . In these figures, each step is related to a section hereafter.

\subsection{Multi-Prosumer Node state-space model}

State-space model is employed to model dynamic devices which are interconnected into the node. These devices are storages, converters, and controllable loads. Employed state-space model with one carrier is described firstly, then augmented state-space model composed of several carriers will be described. Node state-space model is decomposed in specific device types sub-models as detailed below. 


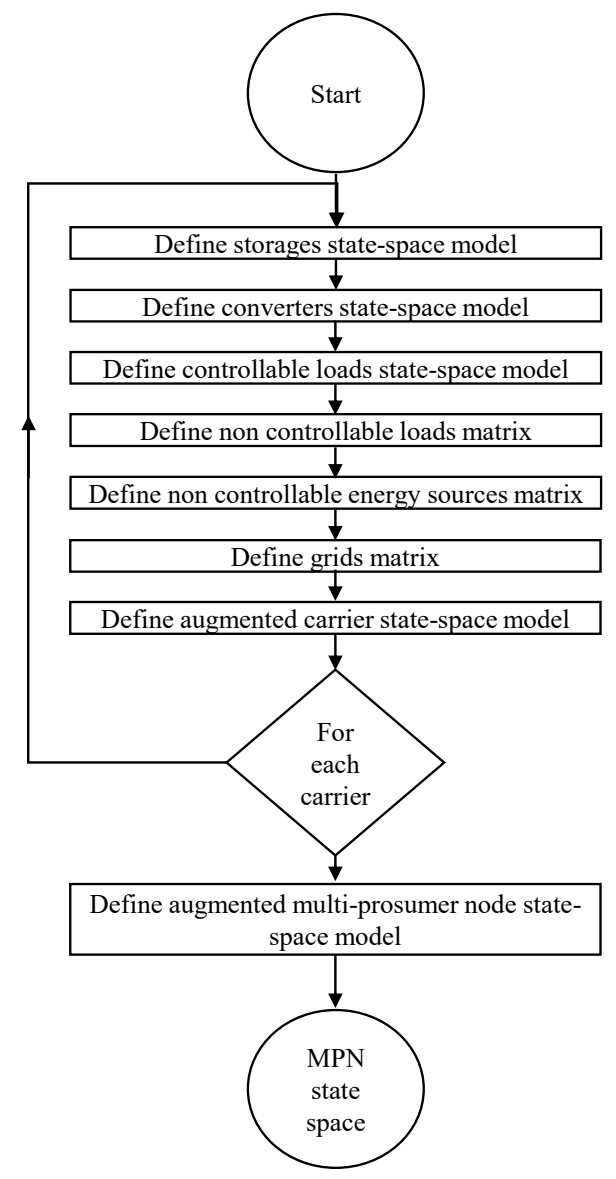

Figure 3: Way to get the state space model (inside the MPN).

\subsubsection{Storages state-space model}

The first device state-space model concerns storage devices. For each energy carrier, the state-space model is equal to:

$$
\dot{x}_{s t}(t)=A_{s t} x_{s t}(t)+B_{u_{s t}} u_{s t}(t)+B_{d_{s t}} d_{s t}(t)
$$

Where $x_{s t}$ is the storage devices state vector, $x_{s t} \in \mathbb{R}^{n_{x_{s t}}}, n_{x_{s t}} \in \mathbb{N}$ is the number of states of storage devices. As whatever kind of state or energy can be regarded, storage devices states can be for instance, a temperature $(\mathrm{K})$ from a thermal storage or an energy in electric vector $(\mathrm{Wh}) . u_{s t}$ is the storage input vector, $u_{s t} \in \mathbb{R}^{n_{u_{s t}}}, n_{u_{s t}} \in \mathbb{N}$ is the number of storage devices' control inputs. It can be a charging power from an electric storage or a heat flow from a thermal storage for example. $d_{s t}$ is the disturbance input vector, $d_{s t} \in \mathbb{R}^{n_{d_{s t}}}, n_{d_{s t}} \in \mathbb{N}$ is the number of storage devices disturbance inputs. $A_{s t}$ is the state matrix, 


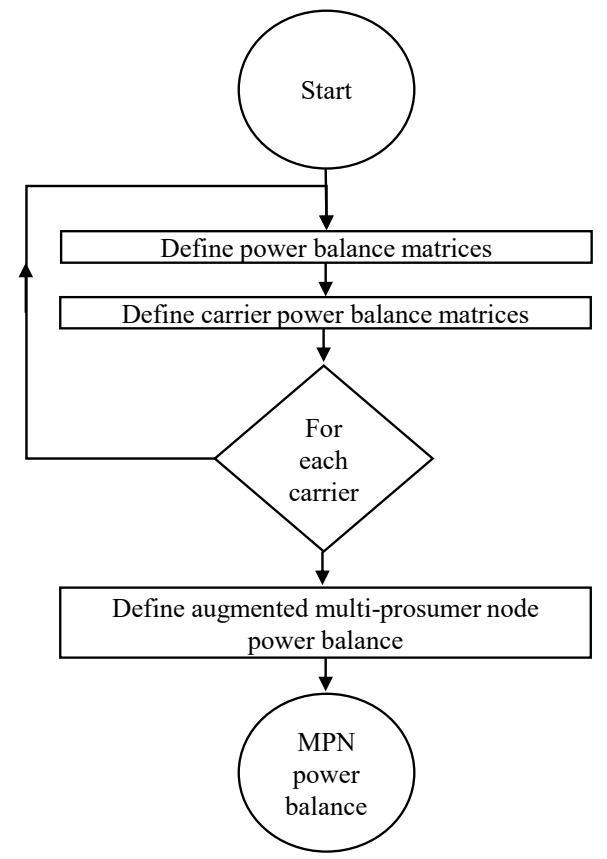

Figure 4: Way to get the power balance (inside the MPN).

$A_{s t} \in \mathbb{R}^{n_{x_{s t}} \times n_{x_{s t}}} . B_{u_{s t}}$ is the input matrix, $B_{u_{s t}} \in \mathbb{R}^{n_{x_{s t}} \times n_{u_{s t}}} . B_{d_{s t}}$ is the

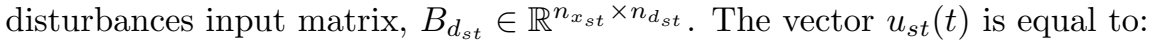

$$
u_{s t}(t)=\left[\begin{array}{lllll}
P 1_{s t_{1}}(t) & P 2_{s t_{1}}(t) & \cdots & P 1_{s t_{N_{s t}}}(t) & P 2_{s t_{N_{s t}}}(t)
\end{array}\right]
$$

Where $P 1_{s t_{i}} \in \mathbb{R}^{+}$is the charging power and $P 2_{s t_{i}} \in \mathbb{R}^{+}$is the discharging power. $i$ from 1 to $N_{s t}$ and $N_{s t} \in \mathbb{N}$ is the amount of storages for this energy carrier.

\subsubsection{Converters state-space model}

The second state-space models are the converter devices. Converters are specific because, they are used to convert an energy carrier into another one, index co stands for converter's output and index $c i$ stands for converter's input. For each energy carrier, the state-space model is equal to:

$$
\dot{x}_{c o}(t)=A_{c t} x_{c o}(t)+B_{u_{c t}} u_{c i}(t)+B_{d_{c t}} d_{c t}(t)
$$

Where $x_{c o}$ is the converters output power, $x_{c o} \in \mathbb{R}^{n_{x_{c o}}}, n_{x_{c o}} \in \mathbb{N}$ are the number of states of converters in the carrier considered. $u_{c i}$ is the converters input vector, $u_{c i} \in \mathbb{R}^{n_{u_{c i}}}, n_{u_{c i}} \in \mathbb{N}$ is the number of converter devices control inputs. $d_{c t}$ is the converter disturbance input vector, $d_{c t} \in \mathbb{R}^{n_{d_{c t}}}, n_{d_{c t}} \in \mathbb{N}$ is the number of converter devices disturbance inputs. $A_{c t}$ is the state matrix, 
$A_{c t} \in \mathbb{R}^{n_{x_{c o}} \times n_{x_{c o}}}$. $B_{u_{c t}}$ is the input matrix, $B_{u_{c o}} \in \mathbb{R}^{n_{x_{c o}} \times n_{u_{c i}}} . B_{d_{c t}}$ is the

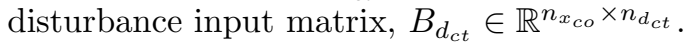

Converter output state power vector can be determined as below:

$$
x_{c o}(t)=\left[\begin{array}{lll}
P_{c O_{1}}(t) & \cdots & P_{c O_{N o}}(t)
\end{array}\right]
$$

Where $P_{c o_{i}}(t) \in \mathbb{R}^{+}$is the power transferred to an energy carrier from converters. $i$ from 1 to $N_{c o}$ and $N_{c o} \in \mathbb{N}$ denotes the number of converters output.

Converter input state power vector is calculated by:

$$
u_{c i}(t)=\left[\begin{array}{lll}
P_{c i_{1}}(t) & \cdots & P_{c i_{N_{c i}}}(t)
\end{array}\right]
$$

Where $P_{c i_{j}} \in \mathbb{R}^{+}$is the power flow extracted by the converters from the energy carrier considered. $j$ from 1 to $N_{c i}$ and $N_{c i} \in \mathbb{N}$ is the sum of all converters which inputs are connected to the energy carrier.

\subsubsection{Controllable loads state-space model}

The third state-space model deals with the controllable loads. They are used to perform load management within the MPN. For each energy carrier, controllable load state-space model is equal to:

$$
\dot{x}_{c l}(t)=A_{c l} x_{c l}(t)+B_{u_{c l}} u_{c l}(t)+B_{d_{c l}} d_{c l}(t)
$$

Where $x_{c l}$ is the controllable devices state vector, $x_{c l} \in \mathbb{R}^{n_{x_{c l}}}, n_{x_{c l}} \in \mathbb{N}$ is the number of states of controllable loads of energy carrier considered. $u_{c l}$ is the controllable loads input vector, $u_{c l} \in \mathbb{R}^{n_{u_{c l}},} n_{u_{c l}} \in \mathbb{N}$ is the number of controllable loads control inputs. $d_{c l}$ is the controllable loads disturbance input vector, $d_{c l} \in \mathbb{R}^{n_{d_{c l}}}, n_{d_{c l}} \in \mathbb{N}$ is the number of controllable loads disturbance inputs. $A_{c l}$ is the state matrix, $A_{c l} \in \mathbb{R}^{n_{x_{c l}} \times n_{x_{c l}} .} B_{u_{c l}}$ is the input matrix, $B_{u_{c l}} \in \mathbb{R}^{n_{x_{c l}} \times n_{u_{c l}}}$. $B_{d_{c l}}$ is the disturbance input matrix, $B_{d_{c l}} \in \mathbb{R}^{n_{x_{c l}} \times n_{d_{c l}}}$.

Controllable loads input state vector power is calculated by following equation:

$$
u_{c l}(t)=\left[\begin{array}{lll}
P_{c l_{1}}(t) & \cdots & P_{c l_{N_{c l}}}(t)
\end{array}\right]
$$

Where, $P_{c l_{i}} \in \mathbb{R}^{+}$is the power flow of the controllable loads connected to the vector. $i$ from 1 to $N_{c l}$ and $N_{c l} \in \mathbb{N}$ is the sum of all connected controllable loads to the energy carrier.

\subsubsection{Non controllable loads matrix}

Non controllable loads are not described by state-space model. They are described as a power disturbance. $d_{n c l}(t)$ is a non controllable load disturbance input vector, $d_{n c l} \in \mathbb{R}^{n_{d_{n c l}}}, n_{d_{n c l}} \in \mathbb{N}$ is the number of non controllable loads disturbance inputs. For each energy carrier, it can be determined as follow:

$$
d_{n c l}(t)=\left[\begin{array}{lll}
P_{n c l_{1}}(t) & \cdots & P_{n c l_{N_{n c l}}}(t)
\end{array}\right]
$$

Where $P_{n c l} \in \mathbb{R}^{+}$is the non-controllable loads power. $i$ from 1 to $N_{n c l}$ and $N_{n c l} \in \mathbb{N}$ is the sum of all non-controllable loads connected to the energy carrier. 


\subsubsection{Non controllable energy sources matrix}

Non controllable generators are not described with state-space model. They are described as a power disturbance. $d_{n c g}(t)$ is a non controllable generators disturbance input vector, $d_{n c g} \in \mathbb{R}^{n_{d_{n c g}}}, n_{d_{n c g}} \in \mathbb{N}$ is the number of non controllable generators disturbance inputs. For each energy carrier, it is equal to:

$$
d_{n c g}(t)=\left[\begin{array}{lll}
P_{n c g_{1}}(t) & \cdots & P_{n c g_{N_{n c g}}}(t)
\end{array}\right]
$$

Where, $P_{n c g_{i}} \in \mathbb{R}^{+}$is the non-controllable generators power. $i$ from 1 to $N_{n c g}$ and $N_{n c g} \in \mathbb{N}$ is the sum of all non-controllable generators connected to the energy carrier.

\subsubsection{Grids matrix}

Grids are not described with state-space model. They are described as a power input. $u_{g r}(t)$ is the grids input vector, $u_{g r} \in \mathbb{R}^{n_{u_{g r}}}, n_{u_{g r}} \in \mathbb{N}$ is the number of grids inputs. It can be described by:

$$
u_{g r}(t)=\left[\begin{array}{lll}
P 1_{g r_{1}}(t) P 2_{g r_{1}}(t) \cdots P 1_{g r_{N g r}}(t) P 2_{g r_{N g r}}(t)
\end{array}\right]
$$

Where, $P 1_{g r_{i}} \in \mathbb{R}^{+}$is the power flow from the grid to the carrier and $P 2_{g r_{i}} \in \mathbb{R}^{+}$ is the power flow from the carrier to the grid. Thus, index $i$ from 1 to $N_{g r}$ denotes number of grids connected to the carrier, and $N_{g r} \in \mathbb{N}$ is the sum of all grids connected to the carrier.

\subsubsection{Augmented carrier state-space model}

Augmented state-space model is used to represent the state-space model of all devices interconnected into the node for one energy carrier $l$. It is equal to:

$$
\dot{x}_{l}(t)=A_{l} x_{l}(t)+B_{u_{l}} u_{l}(t)+B_{d_{l}} d_{l}(t)
$$

Where $x_{l}$ is the energy carrier $l$ state vector, $x_{l} \in \mathbb{R}^{n_{x_{l}}}$. $u_{l}$ is the energy vector input vector, $u_{l} \in \mathbb{R}^{n_{u_{l}}} . d_{l}$ is the energy vector disturbance input vector, $d_{l} \in \mathbb{R}^{n_{d_{l}}}$. Thus, $n_{x_{l}}=n_{x_{s t}}+n_{x_{c o}}+n_{x_{n c l}}, n_{u_{l}}=n_{u_{s t}}+n_{u_{c t}}+n_{u_{n c l}}, n_{d_{l}}=$ $n_{d_{s t}}+n_{d_{c t}}+n_{d_{l n c}}$. Vectors $x_{l}(t), u_{l}(t), d_{l}(t)$ are equal to:

$$
\begin{aligned}
& x_{l}(t)=\left[\begin{array}{lll}
x_{s t}(t) & x_{c o}(t) & x_{c l}(t)
\end{array}\right] \\
& u_{l}(t)=\left[\begin{array}{llll}
u_{s t}(t) & u_{c i}(t) & u_{c l}(t) & u_{g r}(t)
\end{array}\right] \\
& d_{l}(t)=\left[\begin{array}{lllll}
d_{s t}(t) & d_{c t}(t) & d_{c l}(t) & d_{n c l}(t) & d_{n c g}(t)
\end{array}\right]
\end{aligned}
$$

Furthermore, $A_{l}, B_{u_{l}}, B_{d_{l}}$ are adequate dimension and they are formed with diagonal concatenation of device state-space model. $A_{l}$ is formed with $A_{s t}, A_{c t}$, $A_{c l} ; B_{u_{l}}$ with $B_{u_{s t}}, B_{u_{c t}}, B_{u_{c l}} ; B_{d_{l}}$ with $B_{d_{s t}}, B_{d_{c t}}, B_{d_{c l}}$.

\subsubsection{Augmented Multi-Prosumer Node state-space model}

MPN state-space model contains plenty of energy carrier form the node. state-space model provides opportunities to represents dynamics from equip-

ment interconnected into the node. MPN state-space model is composed of an 
augmented state-space model from primary energy carriers. The state-space is equal to:

$$
\dot{x}_{m p n}(t)=A_{m p n} x_{m p n}(t)+B_{u_{m p n}} u_{m p n}(t)+B_{d_{m p n}} d_{m p n}(t)
$$

Where $x_{m p n}$ is the MPN state vector, $x_{m p n} \in \mathbb{R}^{n_{x_{m p n}}}$. $u_{m p n}$ is the MPN input vector, $u_{m p n} \in \mathbb{R}^{n_{u_{m p n}}}$. $d_{m p n}$ is the MPN disturbance input vector, $d_{m p n} \in \mathbb{R}^{n_{d_{m p n}}}$. Moreover, $n_{x_{m p n}}=n_{x_{1}}+\cdots+n_{x_{l}}+\cdots+n_{x_{L}}, n_{u_{m p n}}=$ $n_{u_{1}}+\cdots+n_{u_{l}}+\cdots+n_{u_{L}}, n_{d_{m p n}}=n_{d_{1}}+\cdots+n_{d_{l}}+\cdots+n_{d_{L}}$ and $L$ is the number of carriers in the MPN.Vectors $x_{m p n}(t), u_{m p n}(t), d_{m p n}(t)$ are equal to:

$$
\begin{aligned}
x_{m p n}(t) & =\left[\begin{array}{lllll}
x_{1}(t) & \ldots & x_{l}(t) & \ldots & x_{L}(t)
\end{array}\right] \\
u_{m p n}(t) & =\left[\begin{array}{lllll}
u_{1}(t) & \ldots & u_{l}(t) & \ldots & u_{L}(t)
\end{array}\right] \\
d_{m p n}(t) & =\left[\begin{array}{lllll}
d_{1}(t) & \ldots & d_{l}(t) & \ldots & d_{L}(t)
\end{array}\right]
\end{aligned}
$$

$A_{m p n}$ is the state matrix, $B_{u_{m p n}}$ is the input matrix, $B_{d_{m p n}}$ is the disturbance input matrix. They are adequate dimensions and they are formed with diagonal concatenation of augmented carrier state-space model:

$$
\begin{aligned}
A_{m p n} & =\operatorname{diagonal}\left(\begin{array}{lllll}
A_{1} & \ldots & A_{l} & \ldots & A_{L}
\end{array}\right) \\
B_{u_{m p n}} & =\operatorname{diagonal}\left(\begin{array}{lllll}
B_{u_{1}} & \ldots & B_{u_{l}} & \ldots & B_{u_{L}}
\end{array}\right) \\
B_{d_{m p n}} & =\operatorname{diagonal}\left(\begin{array}{lllll}
B_{d_{1}} & \ldots & B_{d_{l}} & \ldots & B_{d_{L}}
\end{array}\right)
\end{aligned}
$$

Finally, MPN state-space model is discretised in order to manipulate sampled data:

$$
x_{m p n}(k+1)=A_{m p n} x_{m p n}(k)+B_{u_{m p n}} u_{m p n}(k)+B_{d_{m p n}} d_{m p n}(k)
$$

Where, $k$ denotes the sampling period, furthermore the sampling period is constant.

\subsection{Multi-Prosumer Node power balance}

\subsubsection{Power balance}

The power balance for one energy carrier extracted from figure 2 is equal to:

$$
0=P_{g r}(t)-P_{n c l}(t)+P_{n c g}(t)+P_{c o}(t)-P_{c i}(t)-P_{c l}(t)+P_{s t}(t)
$$

Where $P_{g r}$ is the power flow from the grid connected to the carrier, $P_{n c l}$ is the power flow from the non-controllable loads connected to the carrier, $P_{n c g}$ is the power flow from the non-controllable generator connected to the carrier, $P_{c i}$ is the power flow that transforms energy from the carrier to another carrier, $P_{c o}$ is the power flow received by the carrier from another carrier via a converter, $P_{c l}$ is the power flow from controllable loads and $P_{s t}$ is a power flow from or to the storage devices. All units are in watts. The power balance in matrix format 
for one carrier $l$ given $x_{l}, u_{l}(t)$ and $d_{l}(t)$ is equal to:

$$
0=E_{x_{l}} x_{l}(t)+E_{u_{l}} u_{l}(t)+E_{d_{l}} d_{l}(t)
$$

Where $E_{x_{l}}, E_{u_{l}}, E_{d_{l}}$ are the node power balance matrices. Thus, $E_{x_{l}} \in \mathbb{R}^{1 \times n_{x_{l}}}$, $E_{u_{l}} \in \mathbb{R}^{1 \times n_{u_{l}}}, E_{d_{l}} \in \mathbb{R}^{1 \times n_{d_{l}}}$.

Power balance defined with one carrier is described below and afterwards augmented power balance composed of several carriers will be described.

\subsubsection{Power balance matrices}

Matrix $E_{x_{l}}$ is used as output power offset received by converters within energy carrier $l . E_{x_{l}}$ is equal to:

$$
E_{x_{l}}=\left[\begin{array}{lll}
E_{x_{s t}} & E_{x_{c t}} & E_{x_{c l}}
\end{array}\right]^{l}
$$

Where, $E_{x_{s t}}$ is the storage state power balance matrix, $E_{x_{c t}}$ is the converter state power balance matrix within carrier $l, E_{x_{c l}}$ is the controllable loads state power balance matrix. $E_{x_{s t}}, E_{x_{c t}}, E_{x_{c l}}$ are equals to:

$$
\begin{aligned}
& E_{x_{s t}}=[\mathcal{O}] \\
& E_{x_{c t}}=[\mathcal{O}] \\
& E_{x_{c l}}=[\mathcal{O}]
\end{aligned}
$$

Where, $\mathcal{O}$ denotes zero matrix with adequate dimension.

Matrix $E_{u_{l}}$ is employed to model power balance from controllable devices, $E_{u_{l}}$ is equal to:

$$
E_{u_{l}}=\left[\begin{array}{llll}
E_{u_{s t}} & E_{u_{c t}} & E_{u_{c l}} & E_{u_{g r}}
\end{array}\right]^{l}
$$

Where, $E_{u_{s t}}$ is the storage devices power balance. $E_{u_{c t}}$ is the converters input power balance. $E_{u_{c l}}$ is the controllable loads power balance. $E_{u_{g r}}$ is the grids power balance. Matrix $E_{u_{s t}}, E_{u_{g r}}, E_{u_{c t}}, E_{u_{c l}}$ are equal to:

$$
\begin{aligned}
& E_{u_{s t}}=\underbrace{\left[\begin{array}{lll}
-1 & \ldots-1
\end{array}\right]}_{2 \times N_{s t}} \\
& E_{u_{c t}}=\underbrace{\left[\begin{array}{lll}
-1 \ldots-1
\end{array}\right]}_{N_{c i}} \\
& E_{u_{c l}}=\underbrace{\left[\begin{array}{lll}
-1 \ldots-1
\end{array}\right]}_{N_{c l}} \\
& E_{u_{g r}}=\underbrace{\left[\begin{array}{lll}
-11 \ldots-1 & 1
\end{array}\right]}_{2 \times N_{g r}}
\end{aligned}
$$

Where, $N_{s t} \in \mathbb{N}$ is the number of storage devices connected to the carrier. $N_{c i} \in \mathbb{N}$ is the number of converters which inputs from the carrier. $N_{c l} \in \mathbb{N}$ is the number of controllable loads connected to the carrier. $N_{n c l} \in \mathbb{N}$ is the 
number of non controllable loads connected to the carrier. $N_{n c g} \in \mathbb{N}$ is the number of non controllable generators connected to the carrier. $N_{g r} \in \mathbb{N}$ is the number of grids connected to the carrier.

$E_{d_{l}}$ matrix is equal to:

$$
E_{d_{l}}=\left[\begin{array}{lllll}
E_{d_{s t}} & E_{d_{c t}} & E_{d_{c l}} & E_{d_{n c l}} & E_{d_{n c g}}
\end{array}\right]^{l}
$$

Where, $E_{d_{s t}}$ is the disturbance power balance of storage devices, $E_{d_{c t}}$ is the converters disturbance power balance, $E_{d_{c l}}$ is the controllable loads disturbance power balance, $E_{d_{n c l}}$ is the non-controllable loads power balance, $E_{d_{n c g}}$ is the non-controllable generators power balance. $E_{d_{s t}}, E_{d_{c t}}, E_{d_{c l}}, E_{d_{n c l}}$ and $E_{d_{n c g}}$ are equal to:

$$
\begin{aligned}
E_{d_{s t}} & =[\mathcal{O}] \\
E_{d_{c t}} & =[\mathcal{O}] \\
E_{d_{c l}} & =[\mathcal{O}] \\
E_{d_{n c l}} & =\underbrace{[-1 \ldots-1]}_{N_{n c l}} \\
E_{d_{n c g}} & =\underbrace{[1 \ldots 1]}_{N_{n c g}}
\end{aligned}
$$

Where, $N_{n c l} \in \mathbb{N}$ is the number of non-controllable loads connected to the carrier. $N_{n c g} \in \mathbb{N}$ is the number of non-controllable generators connected to the carrier.

\subsubsection{Carrier power balance}

Power balance matrix shape of one carrier is composed of matrices described with respect to equation 24 , it is equal to:

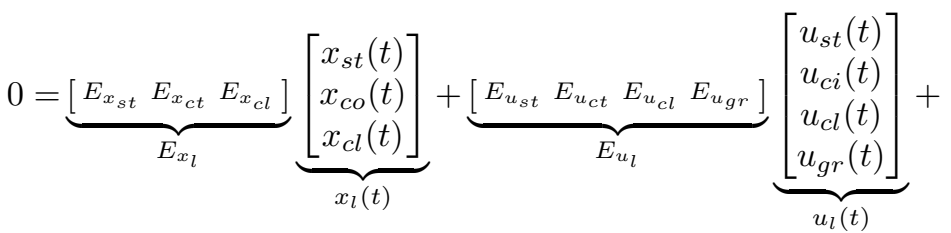

$$
\begin{aligned}
& \underbrace{\left[\begin{array}{lllll}
E_{d_{s t}} & E_{d_{c t}} & E_{d_{c l}} & E_{d_{n c l}} & E_{d_{n c g}}
\end{array}\right]}_{E_{d_{l}}} \underbrace{\left[\begin{array}{c}
d_{s t}(t) \\
d_{c t}(t) \\
d_{c l}(t) \\
d_{n c l}(t) \\
d_{n c g}(t)
\end{array}\right]}_{d_{l}(t)}
\end{aligned}
$$


Which is the power balance expression for one energy carrier $l$ related to equation 24 .

\subsubsection{Augmented Multi-Prosumer Node power balance}

MPN power balance comes when several energy carriers are contained within the node and power balance gives the opportunity to represent power balance from all of these energy carriers. MPN power balance is composed of augmented power balance from all energy carrier.

Matrix $E_{x_{l \rightarrow l^{\prime}}}$ is used to model power balance from converters that transform energy from one carrier $l$ to another carrier $l^{\prime}, E_{x_{l \rightarrow l^{\prime}}}$ is equal to:

$$
E_{x_{l \rightarrow l^{\prime}}}=\left[\begin{array}{lll}
E_{x_{s t_{l} \rightarrow l^{\prime}}} & E_{x_{c t_{l} \rightarrow l^{\prime}}} & E_{x_{c l_{l \rightarrow l^{\prime}}}}
\end{array}\right]
$$

Where, $E_{x_{s t_{l \rightarrow l^{\prime}}}}$ is the storage power balance matrix. $E_{x_{c t_{l} \rightarrow l^{\prime}}}$ is the converter power balance matrix. $E_{x_{c l_{l} \rightarrow l^{\prime}}}$ is the controllable loads power balance matrix.

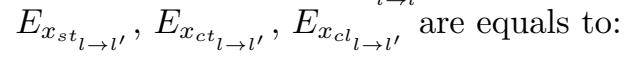

$$
\begin{aligned}
& E_{x_{s t_{l \rightarrow l^{\prime}}}}=[\mathcal{O}] \\
& E_{x_{c t_{l \rightarrow l^{\prime}}}}=\underbrace{}_{N_{c o_{l \rightarrow l^{\prime}}}\left[\begin{array}{lll}
1 & 1
\end{array}\right]} \\
& E_{x_{c l_{l \rightarrow l^{\prime}}}}=[\mathcal{O}]
\end{aligned}
$$

Where, $N_{c o_{l \rightarrow l^{\prime}}} \in \mathbb{N}$ is the number of power converters from carrier $l$ which outputs are connected to the carrier $l^{\prime}$, otherwise, when there is no outputs connections the matrix $E_{x_{c t_{l \rightarrow l}}}$ equals to $\mathcal{O}$. 
MPN power balance is equal to:

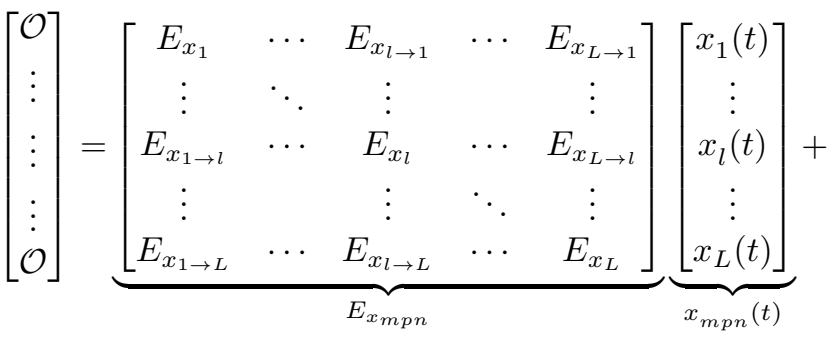

$$
\begin{aligned}
& \underbrace{\left[\begin{array}{ccccc}
E_{u_{1}} & \mathcal{O} & \cdots & \cdots & \mathcal{O} \\
\mathcal{O} & \ddots & \ddots & & \vdots \\
\vdots & \ddots & E_{u_{l}} & \ddots & \vdots \\
\vdots & & \ddots & \ddots & \mathcal{O} \\
\mathcal{O} & \cdots & \cdots & \mathcal{O} & E_{u_{L}}
\end{array}\right]}_{E_{u_{m p n}}} \underbrace{\left[\begin{array}{c}
u_{1}(t) \\
\vdots \\
u_{l}(t) \\
\vdots \\
u_{L}(t)
\end{array}\right]}_{u_{m p n}(t)}+ \\
& \underbrace{\left[\begin{array}{ccccc}
E_{d_{1}} & \mathcal{O} & \cdots & \cdots & \mathcal{O} \\
\mathcal{O} & \ddots & \ddots & & \vdots \\
\vdots & \ddots & E_{d_{l}} & \ddots & \vdots \\
\vdots & & \ddots & \ddots & \mathcal{O} \\
\mathcal{O} & \cdots & \cdots & \mathcal{O} & E_{d_{L}}
\end{array}\right]}_{E_{d_{m p n}}} \underbrace{\left[\begin{array}{c}
d_{1}(t) \\
\vdots \\
d_{l}(t) \\
\vdots \\
d_{L}(t)
\end{array}\right]}_{d_{m p n}(t)}
\end{aligned}
$$

Which summarises to the MPN power balance:

$$
\mathcal{O}=E_{x_{m p n}} x_{m p n}(t)+E_{u_{m p n}} u_{m p n}(t)+E_{d_{m p n}} d_{m p n}(t)
$$

Where $x_{m p n} \in \mathbb{R}^{n_{x_{m p n}}}$ is the MPN power balance state. $u_{m p n} \in \mathbb{R}^{n_{u_{m p n}}}$ is the MPN power balance input vector. $d_{m p n} \in \mathbb{R}^{n_{d_{m p n}}}$ is the MPN power balance disturbance vector. $E_{x_{m p n}}, E_{u_{m p n}}, E_{d_{m p n}}$ are the power balance matrices, they have adequate dimension. Thus, $n_{x_{m p n}}=n_{x_{1}}+\cdots+n_{x_{l}}+\cdots+n_{x_{L}}, n_{u_{m p n}}=$ $n_{u_{1}}+\cdots+n_{u_{l}}+\cdots+n_{u_{L}}, n_{d_{m p n}}=n_{d_{1}}+\cdots+n_{d_{l}}+\cdots+n_{d_{L}}$ and $L$ is the number of vectors that form MPN.

Finally, vectors from power balance and state-space model that form MPN are $X \in\left\{x_{m p n}\right\}, U \in\left\{u_{m p n}\right\}$, and $D \in\left\{d_{m p n}\right\} . X$ and $U$ are decision vectors which are solved by optimisation process and $D$ are the disturbance vectors with no control from the optimisation process. However, disturbances can be measurable and predictable, in this study, all disturbances are considered known and predictions perfect. 


\section{Economic Model Predictive Control}

The control of an energy system with an EMPC algorithm has caught researchers' attention because of its ability to perform optimisation of a cost function over a horizon following the economic optimum. EMPC can take into account the system dynamic, multi-inputs \& multi-outputs systems, constraints from actuators, disturbances and predictions to follow the optimum trajectory $[17,18,19]$. A wide range of systems are controlled with EMPC. For instance, in [55] an EMPC is used to control HVAC (heating and ventilation air-conditioned) with thermal storage within a building. Moreover, in [56] HVAC from a commercial building is controlled thanks to EMPC. In [57] the scheduling of a chemical stirred tank reactor is performed with EMPC. In [3], a supermarket refrigeration, a heat pump, a heat tank with a solar collector and an electric vehicle are controlled thanks to EMPC.

EMPC is solved on a receding horizon, at each time period, states measurement, disturbances measurements, and predictions are received by EMPC. Then, EMPC computes the optimal input trajectory at each sampling time and the first action computed by EMPC (which is the $U$ vector) is sent to the actuators. Then at next sampling time, EMPC process is done again. In this study, grid flows are taken into account with wishes to minimise energy cost extracted from grids. EMPC mathematical formulation is described below:

$$
\begin{aligned}
\min _{c, s} & \sum_{k=1}^{N} c(k)+\rho s(k) \\
\text { s.t. } & x_{m p n}(k+1)=A_{m p n} x_{m p n}(k)+B_{u_{m p n}} u_{m p n}(k)+B_{d_{m p n}} d_{m p n}(k) \\
& 0=E_{x_{m p n}} x_{m p n}(k)+E_{u_{m p n}} u_{m p n}(k)+E_{d_{m p n}} d_{m p n}(k) \\
& x_{m i n}-s(k) \leq x_{m p n}(k) \leq x_{m a x}+s(k) \\
& u_{m i n} \leq u_{m p n}(k) \leq u_{m a x} \\
& 0 \leq s(k) \\
& x_{k=1}=x(t)
\end{aligned}
$$

Where, equation (47) is the cost function with the purpose to minimise operational cost. The operational cost $c$ is specific for each case considered. It could be for instance, the cost of service operation, the sum of energy purchasing cost and the sum of energy selling benefits from the grids. Moreover, a slack variable $s$ and a slack price $\rho$ are introduced, to be able to release states vectors constraints in order to have soft state constraints. Equation (48) is the MPN state-space model. Then, equation (49) is the MPN power balance. Equation (50) is the state vector constraints. Equation (51) is the power constraints applied to the input vector. Equation (52) is the slack variable constraint. Equation (53) is the measurement state at time ( $\mathrm{t}$ ) and $\mathrm{t}$ is the starting point when optimisation is computed. Furthermore, in this study it is assumed that all states are measurable. Studies dedicated to predictive control using state observers are available in $[58,59]$. EMPC formulation has no terminal cost or 
terminal constraints, in that case, states have the possibility to fluctuate inside the constraints.

\section{Case study}

An application of MES controlled by an EMPC and modelled as MPN is presented in this section. Methodology describes in section 2 is applied to the case study.

The application deals with a residential house with a floor area equal to $95 \mathrm{~m}^{2}$ and 6 rooms heated by electrical heaters. The house is connected to electrical utility grid (GR). It is also equipped with photovoltaic panels (NCG) and an electrical storage system (ST). The domestic hot water (DHC) is supplied by a heat pump (CT) coupled by a thermal energy storage (ST). It can be considered that this house is equipped with a MES with two energy carriers: electricity and heat and a converter (the heat pump) which couple them. Therefore, it can be modelled as a MPN and controlled by EMPC. The MPN is presented in figure 5 .

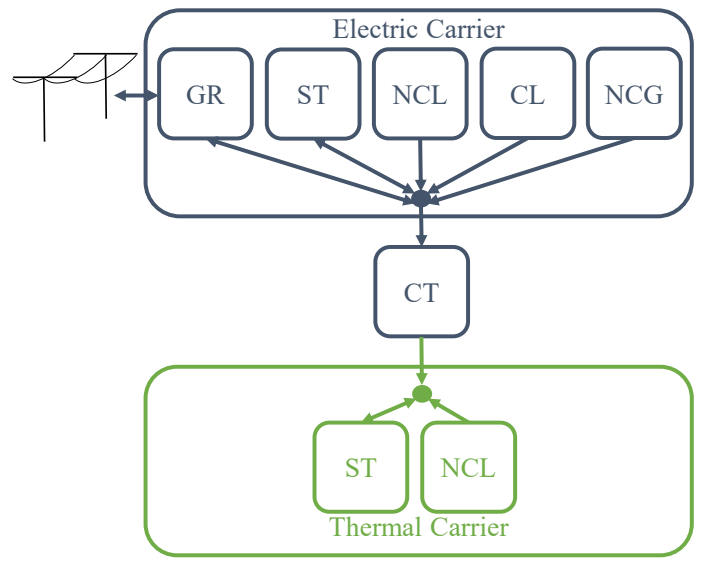

Figure 5: Connected devices to the MPN in this case study (acronyms explanation are visible in figure 2).

For the sake of simplification, table 1 represents devices' acronyms, link between devices acronyms and MPN vectors and link between MPN vectors and used case signals.

\subsection{Electric carrier}

Controllable devices are house heating system, grid connection, converter and battery. Non-controllable devices are loads with no control action and photovoltaic generator. State-space model of controllable devices will be described in the next section. 
Table 1: Devices, MPN and physical indication of use case.

\begin{tabular}{|c|c|c|c|}
\hline Devices & MPN & Electric carrier & Thermal carrier \\
\hline $\mathrm{ST}$ & $x_{s t}(t)$ & $E_{\text {bat }}(t)$ & $T_{t e s}(t)$ \\
\hline $\mathrm{CT}$ & $x_{c o}(t)$ & $\varnothing$ & $Q_{h p}(t)$ \\
\hline $\mathrm{CL}$ & $x_{c l}(t)$ & $T_{a}(t) T_{w, i}(t) T_{w, e}(t)$ & $\varnothing$ \\
\hline $\mathrm{ST}$ & $u_{s t}(t)$ & $P 1_{b a t}(t) P 2_{b a t}(t)$ & $P 1_{\text {tes }}(t) P 2_{\text {tes }}(t)$ \\
\hline $\mathrm{CT}$ & $u_{c i}(t)$ & $P_{h p}(t)$ & $\varnothing$ \\
\hline $\mathrm{CL}$ & $u_{c l}(t)$ & $P_{h t g}(t)$ & $\varnothing$ \\
\hline GR & $u_{g r}(t)$ & $P 1_{\text {grid }}(t) P 2_{\text {grid }}(t)$ & $\varnothing$ \\
\hline $\mathrm{ST}$ & $d_{s t}(t)$ & $\varnothing$ & $T_{\text {room }}(t)$ \\
\hline $\mathrm{CT}$ & $d_{c t}(t)$ & $\varnothing$ & $\varnothing$ \\
\hline $\mathrm{CL}$ & $d_{c l}(t)$ & $Q_{\text {sun } 1}(t) Q_{\text {sun } 2}(t) T_{\text {ext }}(t)$ & $\varnothing$ \\
\hline NCL & $d_{n c l}(t)$ & $P_{n c l_{e}}(t)$ & $P_{n c l_{t}}(t)$ \\
\hline NCG & $d_{n c g}(t)$ & $P_{p v}(t)$ & $\varnothing$ \\
\hline
\end{tabular}

\subsubsection{State-space of storage devices}

The storage system is is based on a battery. The energy derivative can be represented by [14]:

$$
\dot{E}_{b a t}(t)=\eta P_{b a t}(t)
$$

Where, $E_{b a t}$ is the stored energy in J, $P_{b a t}$ is the power in $\mathrm{W}$ and $\eta$ is the charging or discharging efficiencies, without units. In order to model bidirectional power from the battery system and with discretised matrix, the electric storage statespace model is extracted from [23]:

$$
\left[E_{b a t}(k+1)\right]=\left[E_{b a t}(k)\right]+\left[\eta_{c h} \Delta t-\frac{1}{\eta_{d c h}} \Delta t\right]\left[\begin{array}{l}
P 1_{b a t}(k) \\
P 2_{b a t}(k)
\end{array}\right]
$$

Where, $E_{b a t}$ is the stored energy in Wh, $\eta_{c h}$ and $\eta_{d c h}$ are the dimensionless values for the charging and discharging efficiencies and $\Delta t$ is the sampling time. $P 1_{b a t}$ is the charging power in $\mathrm{W}$ and $P 2_{b a t}$ is the discharging power in $\mathrm{W}$. Links from device's acronym and MPN is mentioned in table $1 . E_{b a t}(t)$ is the state $x_{s t}(t)$ from the electrical carrier while the battery power $\left(P 1_{b a t}(t), P 2_{b a t}(t)\right)$ form control input $u_{s t}$.

\subsubsection{State-space model of the converter}

The converter transforms energy from electric carrier to thermal carrier (from carrier one to carrier two), with the aim to heat up domestic water. The converter is a heat pump. There are plenty of heat pump technologies [31]. Dynamic heat pump responses can be seen in $[32,33]$. In this study, the heat pump system output power is modelled as a first order linear system. The 


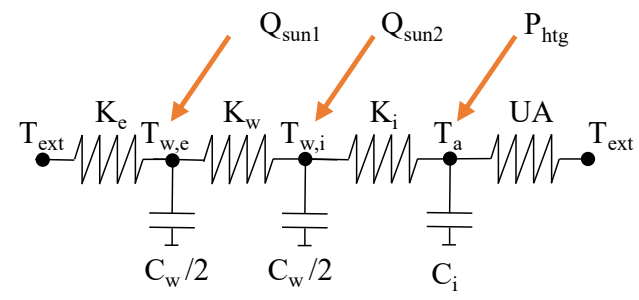

Figure 6: The equivalent thermal model, derived from [37].

first-order model is:

$$
\underbrace{\left[\dot{Q}_{h p}(t)\right]}_{\dot{x}_{c o}(t)}=\underbrace{\left[-\frac{1}{\tau_{h p}}\right]}_{A_{c t}} \underbrace{\left[Q_{h p}(t)\right]}_{x_{c o}(t)}+\underbrace{\left[\frac{K_{h p}}{\tau_{h p}}\right]}_{B_{u_{c t}}} \underbrace{\left[P_{h p}(t)\right]}_{u_{c i}(t)}
$$

Where, $Q_{h p}$ is the delivery heating in $\mathrm{W}, \tau_{h p}$ is the time constant in seconds, $K_{h p}$ is the steady state efficiency of the heat pump which is the heat pump coefficient of performance, without units, and $P_{h p}$ is the heat pump electric power in $\mathrm{W}$.

\subsubsection{State-space of the controllable loads}

The heating system is a good candidate to allow the load management [34, $35,36]$, because of its ability to use the walls as storage, thanks to their inertia. In this study, the building is considered as a controllable load, in other case studies, it could be modelled as loads or storage with heat losses. The building model used in this study is a first order linear model simplification technique with resistance and capacitance. The equivalent thermal model is taken from [37], and it can be seen in figure 6. Moreover, the equivalent thermal resistance is derived with the assumption of a plane wall. State-space model of equivalent thermal building model from [37] can be described as follows:

$$
\begin{gathered}
\underbrace{\left[\begin{array}{c}
\dot{T}_{a}(t) \\
\dot{T}_{w, i}(t) \\
\dot{T}_{w, e}(t)
\end{array}\right]}_{\dot{x}_{c l}(t)}=\underbrace{\left[\begin{array}{ccc}
-\frac{U A+K_{i}}{C_{i}} & \begin{array}{c}
K_{i} \\
C_{i}
\end{array} & 0 \\
C_{w} / 2 & -\frac{K_{w}+K_{i}}{C_{w} / 2} & \frac{K_{w}}{C_{w} / 2} \\
0 & \frac{K_{w}}{C_{w} / 2} & -\frac{K_{e}+K_{w}}{C_{w} / 2}
\end{array}\right]}_{A_{c l}} \underbrace{\left[\begin{array}{c}
T_{a}(t) \\
T_{w, i}(t) \\
T_{w, e}(t)
\end{array}\right]}_{x_{c l}(t)}+ \\
\underbrace{\left[\begin{array}{c}
\frac{1}{C_{i}} \\
0 \\
0
\end{array}\right]}_{B_{u_{c l}}} \underbrace{\left[P_{h t g}(t)\right]}_{u_{c l}(t)}+\underbrace{\left[\begin{array}{ccc}
0 & 0 & \frac{U A}{C_{i}} \\
0 & \frac{1}{C_{w} / 2} & 0 \\
\frac{1}{C_{w} / 2} & 0 & \frac{K_{e}}{C_{w} / 2}
\end{array}\right]}_{B_{d_{c l}}} \underbrace{\left[\begin{array}{c}
Q_{\text {sun } 1}(t) \\
Q_{\text {sun } 2}(t) \\
T_{e x t}(t)
\end{array}\right]}_{d_{c l}(t)}
\end{gathered}
$$

Where $K_{e}$ is the heat transfer coefficient by convection from outdoor wall to outside in $\frac{\mathrm{W}}{\mathrm{K}}$. $K_{w}$ is the heat transfer coefficient by conduction through concrete and insulation building in $\frac{\mathrm{W}}{\mathrm{K}}$. $K_{i}$ is the heat transfer coefficient by convection 
from indoor wall to inside air in $\frac{\mathrm{W}}{\mathrm{K}}$. $U A$ is the heat transfer coefficient related to ventilation heat loss in $\frac{\mathrm{W}}{\mathrm{K}}$. $C_{w}$ is the concrete wall thermal mass in $\frac{\mathrm{J}}{\mathrm{K}}$. $C_{i}$ is the air thermal mass in $\frac{\mathrm{J}}{\mathrm{K}}$. Also, $T_{a}$ is the indoor air temperature in ${ }^{\circ} \mathrm{C}$, $T_{w, i}$ is the wall internal surface temperature in ${ }^{\circ} \mathrm{C}$ and $T_{w, e}$ is the wall external surface temperature in ${ }^{\circ} \mathrm{C}, T_{\text {ext }}$ is the outdoor temperature in ${ }^{\circ} \mathrm{C} . Q_{\text {sun } 1}$ is the solar radiation that gets to external wall in W. $Q_{\text {sun } 2}$ is the solar radiation that reaches internal wall through glazing in W. $P_{h t g}$ is the building heating power in $\mathrm{W}$.

\subsection{Thermal carrier}

Devices are divided into two groups, the first one is composed of the equipment that the controller is able to control and the second is composed of equipment which can not be controlled. The water tank forms the controllable devices and loads form the non-controllable ones. State-space model of the thermal storage will be described in the next section.

\subsubsection{State-space of the storage device}

The thermal storage is formed by the water tank, with the ability to store heat. Water temperature is studied and the thermal storage is simplified with a first order linear model, it is extracted from [42]. It can be represented as below formula:

$$
C_{\text {tes }} \dot{T}_{\text {tes }}(t)=U_{\text {tes }}\left(T_{\text {room }}(t)-T_{\text {tes }}(t)\right)+P(t)
$$

The state-space model of the thermal storage device is equal to:

$$
\begin{aligned}
& \underbrace{\left[\dot{T}_{\text {tes }}(t)\right]}_{\dot{x}_{s t}(t)}=\underbrace{\left[-\frac{U_{\text {tes }}}{C_{\text {tes }}}\right]}_{A_{s t}} \underbrace{\left[T_{\text {tes }}(t)\right]}_{x_{s t}(t)}+ \\
& \underbrace{\left[\frac{1}{C_{\text {tes }}}-\frac{1}{C_{\text {tes }}}\right]}_{B_{u_{s t}}} \underbrace{\left[\begin{array}{l}
P 1_{\text {tes }}(t) \\
P 2_{\text {tes }}(t)
\end{array}\right]}_{u_{s t}(t)}+\underbrace{\left[\frac{U_{\text {tank }}}{C_{\text {tes }}}\right]}_{B_{d_{s t}}} \underbrace{\left[T_{\text {room }}(t)\right]}_{d_{s t}(t)}
\end{aligned}
$$

Where, $T_{\text {tes }}$ is the storage temperature inside the storage tank in ${ }^{\circ} \mathrm{C} . U_{\text {tes }}$ is the thermal conductance in $\frac{\mathrm{W}}{\mathrm{K}}$. $C_{\text {tes }}$ is the heat capacity in $\frac{\mathrm{J}}{\mathrm{K}} \cdot T_{\text {room }}$ is the temperature where the storage is located in ${ }^{\circ} \mathrm{C} . P 1_{\text {tes }}$ is the charging power and $P 2_{\text {tes }}$ is the discharging power, both units are in $\mathrm{W}$.

\subsection{Multi-Prosumer Node state-space model}

The MPN state-space model is formed of state-space models from electrical and thermal carriers, it is shown by equation (60). 


$$
\begin{aligned}
& \underbrace{\left[\begin{array}{c}
\dot{E}_{b a t}(t) \\
\dot{Q}_{h p}(t) \\
\dot{T}_{a}(t) \\
\dot{T}_{w, i}(t) \\
\dot{T}_{w, e}(t) \\
\dot{T}_{t e s}(t)
\end{array}\right]}_{\dot{x}_{m p n}(t)}=\underbrace{\left[\begin{array}{cccccc}
0 & 0 & 0 & 0 & 0 & 0 \\
0 & -\frac{1}{\tau_{h p}} & 0 & 0 & 0 & 0 \\
0 & 0 & -\frac{U A+K_{i}}{C_{i}} & \frac{K_{i}}{C_{i}} & 0 & 0 \\
0 & 0 & \frac{K_{i}}{C_{w} / 2} & -\frac{K_{w}+K_{i}}{C_{w} / 2} & \frac{K_{w}}{C_{w} / 2} & 0 \\
0 & 0 & 0 & \frac{K_{w}}{C_{w} / 2} & -\frac{K_{e}+K_{w}}{C_{w} / 2} & 0 \\
0 & 0 & 0 & 0 & 0 & -\frac{U_{t e s}}{C_{t e s}}
\end{array}\right]}_{A_{m p n}} \underbrace{\left[\begin{array}{c}
E_{b a t}(t) \\
Q_{h p}(t) \\
T_{a}(t) \\
T_{w, i}(t) \\
T_{w, e}(t) \\
T_{\text {tes }}(t)
\end{array}\right]}_{x_{m p n}(t)}+ \\
& \underbrace{\left[\begin{array}{cccccccc}
\eta_{c h} & -\frac{1}{\eta_{d c h}} & 0 & 0 & 0 & 0 & 0 & 0 \\
0 & 0 & \frac{K_{h p}}{\tau_{h p}} & 0 & 0 & 0 & 0 & 0 \\
0 & 0 & 0 & \frac{1}{C_{i}} & 0 & 0 & 0 & 0 \\
0 & 0 & 0 & 0 & 0 & 0 & 0 & 0 \\
0 & 0 & 0 & 0 & 0 & 0 & 0 & 0 \\
0 & 0 & 0 & 0 & 0 & 0 & \frac{1}{C_{t e s}} & -\frac{1}{C_{\text {tes }}}
\end{array}\right]}_{B_{u_{m p n}}} \underbrace{\left[\begin{array}{c}
P 1_{\text {bat }}(t) \\
P 2_{\text {bat }}(t) \\
P_{h p}(t) \\
P_{h t g}(t) \\
P 1_{\text {grid }}(t) \\
P 2_{\text {grid }}(t) \\
P 1_{\text {tes }}(t) \\
P 2_{\text {tes }}(t)
\end{array}\right]}_{u_{m p n}(t)}+ \\
& \underbrace{\left[\begin{array}{ccccccc}
0 & 0 & 0 & 0 & 0 & 0 & 0 \\
0 & 0 & 0 & 0 & 0 & 0 & 0 \\
0 & 0 & \frac{U A}{C_{i}} & 0 & 0 & 0 & 0 \\
0 & \frac{1}{C_{w} / 2} & 0 & 0 & 0 & 0 & 0 \\
\frac{1}{C_{w} / 2} & 0 & \frac{K_{e}}{C_{w} / 2} & 0 & 0 & 0 & 0 \\
0 & 0 & 0 & \frac{U_{t e s}}{C_{t e s}} & 0 & 0 & 0
\end{array}\right]}_{B_{d_{m p n}}} \underbrace{\left[\begin{array}{c}
Q_{\text {sun } 1}(t) \\
Q_{\text {sun }}(t) \\
T_{\text {ext }}(t) \\
T_{r o o m}(t) \\
P_{n c l_{e}}(t) \\
P_{p v}(t) \\
P_{n c l_{t}}(t)
\end{array}\right]}_{d_{m p n}(t)}
\end{aligned}
$$

Where, $P 1_{\text {grid }}$ and $P 2_{\text {grid }}$ are the grid power (from MPN to grid and from grid to MPN) in W. $P_{n c l}$ is the non-controllable load in electric carrier in W. $P_{p v}$ is the photovoltaic power in W. $P_{n c l_{t}}$ is the non-controllable load in thermal carrier in W. Other symbols and subscripts were presented in sections 4.1 and 4.2. They are not mentioned here for conciseness.

\subsection{Multi-Prosumer Node power balance}

MPN power balance is formed of power balance from carrier one and carrier two, it is described by to equation (61). 


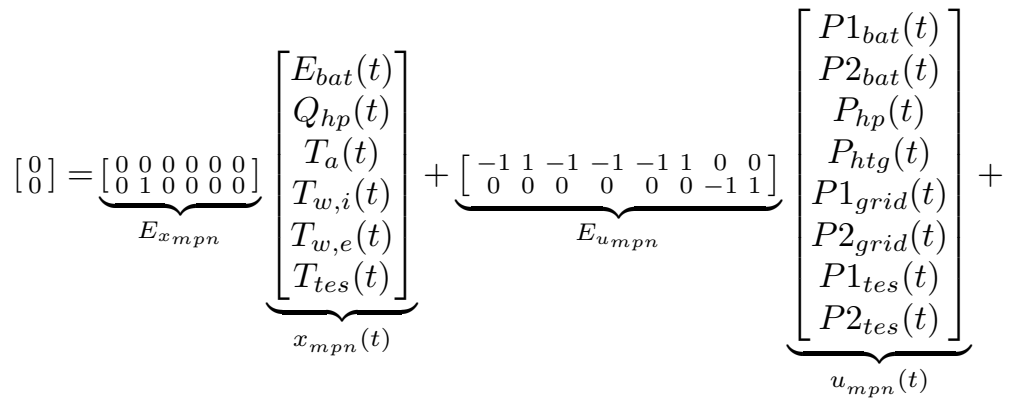

$$
\begin{aligned}
& \underbrace{\left[\begin{array}{cccccc}
0 & 0 & 0 & -1 & 1 & 0 \\
0 & 0 & 0 & 0 & 0 & -1
\end{array}\right]}_{E_{d_{m p n}}} \underbrace{\left[\begin{array}{c}
Q_{\text {sun } 1}(t) \\
Q_{\text {sun } 2}(t) \\
T_{\text {ext }}(t) \\
T_{\text {room }}(t) \\
P_{n c l_{e}}(t) \\
P_{\text {pv }}(t) \\
P_{n c l_{t}}(t)
\end{array}\right]}_{d_{m p n}(t)}
\end{aligned}
$$

\subsection{Simulation models}

In order to experiment the control based on MPN and EMPC, a realistic model is considered within the Simulink framework, especially involving Simscape [39]. Control and simulation models are split according to figure 7 . The battery considered is based on the Power System battery model as in [38]. Thermal storage model is built with Simscape [39], further building model is also built with toolbox Simscape. The converter simulation model is built as a transfer function block of Simulink. Simulink solver used to perform the simulation is ode4 (Runge-Kutta) with a fixed-step of $0.1 \mathrm{~s}$, also, no local solver configuration is applied with Simscape models. Thus, simulation is performed with an Intel Xeon Gold, Windows 10 and Matlab/Simulink version R2018a.

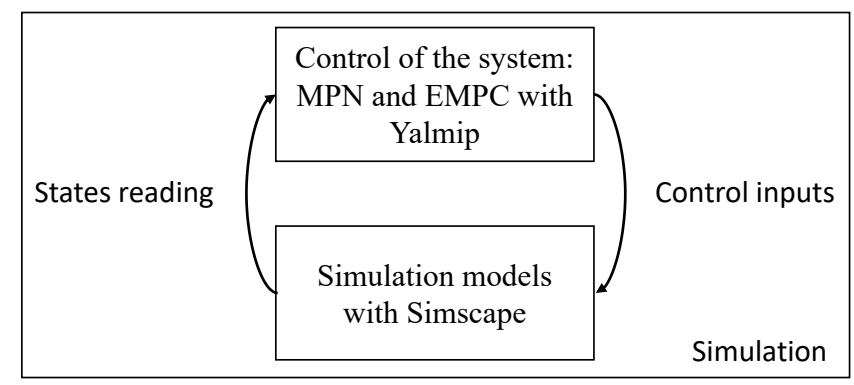

Figure 7: Links between control and simulation models.

In real life, the box "simulation models" is replaced by the real MES, and control is performed thanks to a remote computing machine involving MPN 
model and EMPC. This controller computes the actuators' input from the current MES state available from sensors and overall policy elements.

\subsection{EMPC tuning}

The control is composed of MPN, detailed in section 4, and EMPC presented in section 3. Models are discretised with Matlab command $c 2 d$ with bilinear Tustin method. However, the discretisation with $c 2 d$ is not applied to the battery model but its discretisation state-space is taken from equation (55). The optimisation problem is linear and is implemented in Yalmip [40]. Solver used is CLP [41] with interior point method (barrier), and maximum number of iterations is modified to 10000. EMPC is solved with a horizon of 24 hours, and a step time of 5 minutes, which gives 288 steps. The EMPC dynamic models are discretised with 5 minutes sample times and all state and predictions are perfectly known. The parameters of MPN models calculated by equation (60) can be seen in table 2, and EMPC constraints can be seen in table 3 .

Table 2: Parameters of MPN state-space models.

\begin{tabular}{cc}
\hline Parameters & Data \\
\hline$\tau_{h p}$ & $2 \mathrm{~min}$, from $[32]$ \\
$K_{h p}$ & 3, assumed \\
$C_{i}$ & $277611 \mathrm{~J} \mathrm{~K}^{-1}$ \\
$C_{w}$ & $61839000 \mathrm{~J} \mathrm{~K}^{-1}$ \\
$K_{e}$ & $3183 \mathrm{~W} \mathrm{~K}^{-1}$ \\
$K_{w}$ & $25.03 \mathrm{~W} \mathrm{~K}^{-1}$ \\
$K_{i}$ & $3183 \mathrm{~W} \mathrm{~K}^{-1}$ \\
$U A$ & $55 \mathrm{~W} \mathrm{~K}^{-1}$, assumed $^{-1}$ \\
$U_{\text {tes }}$ & $3.31 \mathrm{~W} \mathrm{~K}^{-1}$ \\
$C_{\text {tes }}$ & $837000 \mathrm{~J} \mathrm{~K}^{-1}$ \\
$\left\{\eta_{\text {ch }}, \eta_{\text {dch }}\right\}$ & 0.9, assumed \\
$T_{\text {room }}$ & $15{ }^{\circ} \mathrm{C}$, assumed \\
\hline
\end{tabular}

Table 3: EMPC constraints.

\begin{tabular}{ccc}
\multicolumn{3}{c}{ Table 3: EMPC constraints. } \\
\hline Minimum & Parameters & Maximum \\
\hline $0 \mathrm{~W}$ & $\left\{P 1_{\text {bat }}, P 2_{\text {bat }}\right\}$ & $1.1 \mathrm{~kW}$ \\
$0 \mathrm{~W}$ & $\left\{P 1_{\text {grid }}, P 2_{\text {grid }}\right\}$ & $20 \mathrm{~kW}$ \\
$0 \mathrm{~W}$ & $P_{h p}$ & $3.5 \mathrm{~kW}$ \\
$0 \mathrm{~W}$ & $P_{\text {htg }}$ & $9 \mathrm{~kW}$ \\
$0 \mathrm{~W}$ & $\left\{P 1_{\text {tes }}, P 2_{\text {tes }}\right\}$ & $24 \mathrm{~kW}$ \\
$0.33 \mathrm{~kW} \mathrm{~h}^{-1}$ & $E_{\text {bat }}$ & $3.3 \mathrm{~kW} \mathrm{~h}^{-1}$ \\
$20^{\circ} \mathrm{C}$ & $T_{\text {buil }}$ & $28^{\circ} \mathrm{C}$ \\
$55^{\circ} \mathrm{C}$ & $T_{\text {tes }}$ & $75{ }^{\circ} \mathrm{C}$ \\
\hline
\end{tabular}




\subsection{Case study properties}

House floor area is equal to $95 \mathrm{~m}^{2}$, wall and insulation thickness are respectively $0.1 \mathrm{~m}$ and $0.4 \mathrm{~m}$. Moreover, wall height is $2.5 \mathrm{~m}$ and rated electric heater is $1.5 \mathrm{~kW}$, see table 4 . Thermal storage and heat pump are assumed to be installed in a cellar with constant temperature and constant water supply, these lead to constant ambiant temperature for these systems. The time response and coefficient of performance of the heat pump are taken from [32]. Building thermal parameters can be seen in table 2. Heat transfer is calculated once and it is assumed constant during the simulation. Also, glass windows of the building are assumed to be $5 \mathrm{~m}^{2}$ and $Q_{\text {sun } 1}$ pass across the windows area. Thermal storage is assumed to be a 200L capacity, see table 4, and the thermal leakage resistance is calculated with a heat transfer of $0.6 \mathrm{~W} \mathrm{~m}^{-2} \mathrm{~K}^{-1}$ taken from [42]. The battery system parameters are derived from the manufacturer's data [43], rated energy is $3.3 \mathrm{~kW} \mathrm{~h}^{-1}$, see table 4 . Grid power constraints are derived from [44]. Furthermore, the slack price of the slack variable is equal to $1 \times 10^{15}$.

The operating cost $c$ is composed of the economic cost from energy swap with grid (grid pricing). It is a cost when energy is imported denoted $c_{g r}$ and it is a gain denoted $v_{g r}$ when energy is injected. $c$ is equal to:

$$
\begin{aligned}
c(k) & =c_{u}(k) u_{g r}(k) \\
c_{u}(k) & =\left[\begin{array}{ll}
-v_{g r}(k), \quad c_{g r}(k)
\end{array}\right]
\end{aligned}
$$

Grid pricing is composed of time-of-use (TOU) tariff, it is a time-varying price with a peak rate and off-peak rate [45]. TOU is chosen in this study, because it is used by many worldwide utilities as incentives in order to enable consumers to be part of demand response programs [46, 47]. TOU tariff is defined by two prices during a day, the first price is the high tariff with $€ 15.79 \mathrm{c}$ per $\mathrm{kW} \mathrm{h}$ from $6 \mathrm{~h} 30$ to $22 \mathrm{~h} 30$, and the second is low tariff with $€ 12.28 \mathrm{c}$ per $\mathrm{kW} \mathrm{h}$ from $22 \mathrm{~h} 30$ to 6h30. These tariffs are taken from the regulated rate utilities in France [44]. The sell tariff of MPN energy keeps constant during all the day time by the price of $€ 10 \mathrm{c}$ per $\mathrm{kW}$ h, which is also taken from regulated rate utilities in France [48]. Grid tariffs are the same in all scenarios presented in this study.

Table 4: Related parameters of the real case application.

\begin{tabular}{cc}
\hline Parameters & Data \\
\hline Floor area & $95 \mathrm{~m}^{2}$ \\
Glass windows & $5 \mathrm{~m}^{2}$ \\
Wall thickness & $0.1 \mathrm{~m}$ \\
Insulation thickness & $0.4 \mathrm{~m}$ \\
Wall height & $2.5 \mathrm{~m}$ \\
Thermal storage & $200 \mathrm{~L}$ \\
Electrical storage & $3.3 \mathrm{~kW} \mathrm{~h}^{-1}$ \\
One electric heater power & $1.5 \mathrm{~kW}$ \\
\hline
\end{tabular}




\subsection{Benchmarks}

In order to assess MPN performance, two benchmarks were built for the sake of comparison. The first benchmark is made of three separate control procedures and it focused on charging the battery when photovoltaic energy is produced. The second benchmark is also composed of three control strategies similar to the benchmark I. However charging process of both electric and thermal storage are modified in order to maximising self-consumption of energy when it is produced by photovoltaic generators.

\subsubsection{Benchmark I}

The first benchmark has three controls designed to handle house temperature, hot water storage and battery respectively. Each of these controls are working separately as described below:

- The temperature of the house is regulated invariably at $20^{\circ} \mathrm{C}$, with a PI controller.

- Hot water storage regulation is active in case of an incentive grid tariff while the heat pump remains off when the grid tariff is high. A bang-bang controller is used (also called on-off controller [49]) with a hysteresis at the set-points from $73^{\circ} \mathrm{C}$ till $75^{\circ} \mathrm{C}$.

- The battery is charged when solar power generation is available and discharged otherwise, if loads request power. The solar production is dispatched first to the battery, second to the loads and finally to the grid. This control is replicated from industrial self-consumption kit which they are commercially available nowadays $[50,51]$.

\subsubsection{Benchmark II}

The second benchmark has three controls to handle house temperature, hot water storage and battery. Additionally, hot water storage and battery are working with photovoltaic generators:

- The temperature of the house is regulated invariably at $20^{\circ} \mathrm{C}$, with a PI controller.

- Hot water storage regulation is active in case of an incentive grid tariff and photovoltaic energy production, while the heat pump remains off when the grid tariff is high and photovoltaic energy is no longer available. A bangbang controller is used (also called on-off controller [49]) with a hysteresis at the set-points from $73^{\circ} \mathrm{C}$ till $75^{\circ} \mathrm{C}$.

- The battery is charging when solar power generation is available and discharging in the case of power requested by the loads.

- The solar production dispatches to: first the loads, second the battery, third the thermal storage and fourth the grid. 


\subsection{Simulation scenarios}

In this research, two scenarios have been studied, namely, 1-winter and 2summer day. Winter day has been studied due to its importance, as the weather is cold, photovoltaic generation is low and energy demand is high. By contrast, in a typical summer day, it is expected that the energy demand is lower and photovoltaic energy is more available. In this study, loads data are taken from CREST model, this model is able to deliver heat and electricity simulation data for housing in minute scale from Leicestershire in England [52]. Sun's radiation and outside temperature are taken from HELIOCLIM-3 archives [53]. For the sake of consistency with the CREST model, the location of HELIOCLIM-3 data was specified at Leicestershire. It should be noted that the simulation was run for 48 hours and divided to two equal periods of 24 hours: the first 24 hours data were run in order to stabilise the building model and the second 24 hours data are reported in this paper.

\section{Results}

Plots in figures 8, 9 and 10 have right and left ordinates. The left ordinate in black corresponds to data in black and right ordinates in red with data in red. Furthermore, the legend is displayed for each subplot. Finally, filigrees highlight information discussed in the results section and help to focus on selective time windows. These three figures focus on the winter scenario.

Figure 8 depicts the results from benchmark I. The first three plots depict input data, figures 8.a, 8.b and 8.c. It can be noticed (figure 8.d) that the building temperature $T_{a}$ Bench.I remains constant over time.

Moreover, blue filigrees from $27 \mathrm{~h}$ to $27.35 \mathrm{~h}, 28.26 \mathrm{~h}$ to $28.8 \mathrm{~h}$ and $46.5 \mathrm{~h}$ to $47.14 \mathrm{~h}$ highlight the increasing thermal storage temperature $\left(T_{\text {tes }}\right.$ Bench.I, figure 8.f). It climbs to $75^{\circ} \mathrm{C}$. Also, $T_{\text {tes }}$ Bench.I, at 24 hours is equal to $75^{\circ} \mathrm{C}$. The thermal storage temperature is loaded in accordance to the second controller built with a bang-bang controller which is on when the grid tariff is low. The thermal temperature is heated up to maximum temperature and the control did not reduce heat losses.

Furthermore, it can be seen from $32.68 \mathrm{~h}$ to $39.88 \mathrm{~h}$ (highlighted in red filigree), that photovoltaic power is available, 8.a. Three main events are visible:

- At the beginning of the period, from $32.68 \mathrm{~h}$ to $36.78 \mathrm{~h}$, the PV production is used to charge the battery, figure 8.g.

- From $36.78 \mathrm{~h}$ to $39.88 \mathrm{~h}$, the PV production powered the heating system, figure 8.d, or even sold only when the battery $S O C_{b a t}$ Bench.I is fully charged, figure 8.g and $P_{g r}$ Bench.I is lower than 0W, figure 8.e. In addition, the power heating system $P_{h t g}$ Bench.I gradually decreased when the sun heated the building $Q_{\text {sun } 1}$, figure 8.d and figure 8.a.

- After $39.88 \mathrm{~h}, \mathrm{PV}$ power is not available anymore, the battery is discharged, figure 8.g, and the imported energy from the grid is null. In addition, when 


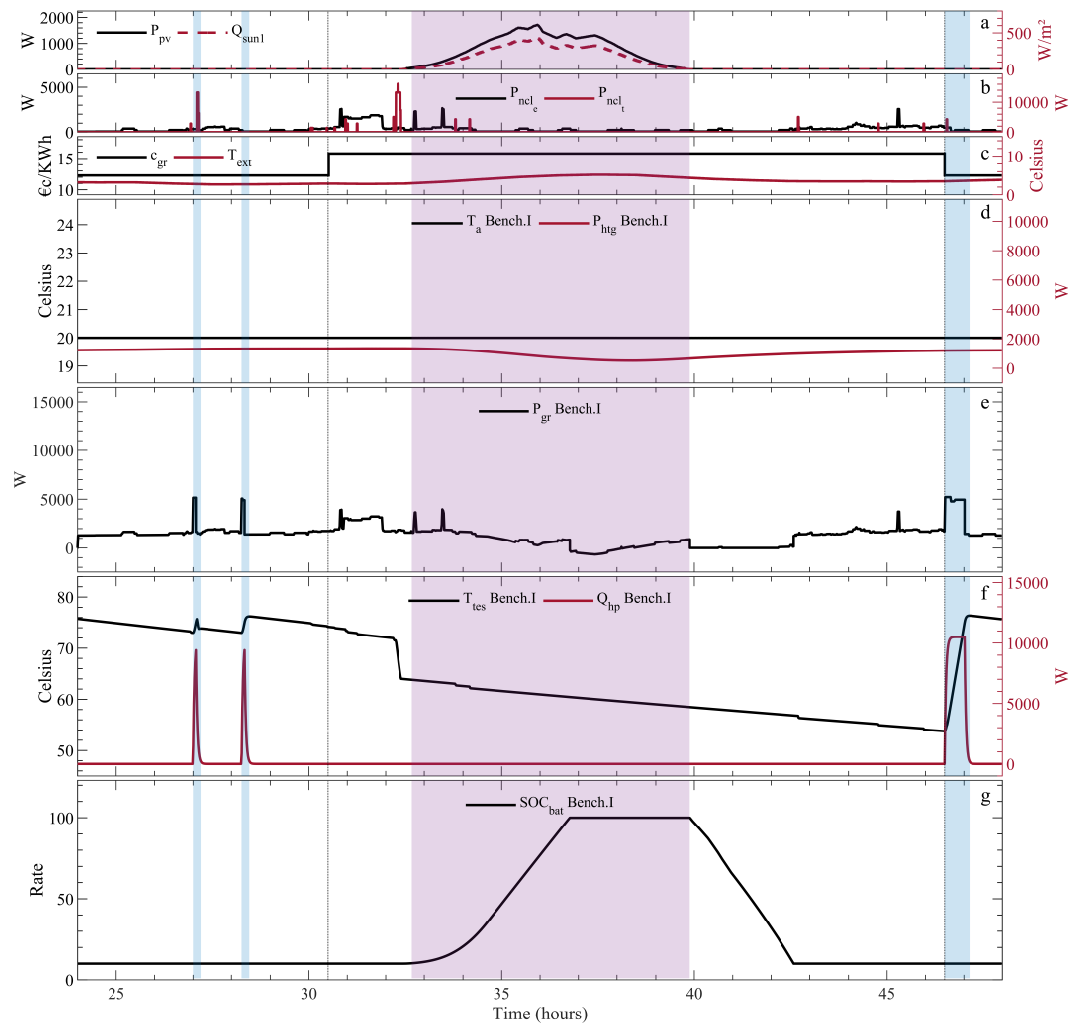

Figure 8: Simulation results with benchmark I. Figure 8.a depicts photovoltaic power $P_{p v}$ and sun heat $Q_{\text {sun } 1}$. Figure 8.b depicts non-controllable loads from electric carrier $P_{n c l}$ and thermal carrier $P_{n c l_{t}}$. Figure 8.c depicts grid cost $c_{g r}$ and outdoor temperature $T_{\text {ext }}$. Figure 8.d depicts indoor air temperature $T_{a}$ and building heating power $P_{h t g}$. Figure 8.e depicts grid power $P_{g r}$. Figure 8 .f depicts thermal storage temperature $T_{t e s}$ and converter delivery heating $Q_{h p}$. Figure 8.g depicts battery stored energy as state of charge $S O C_{b a t}$. 


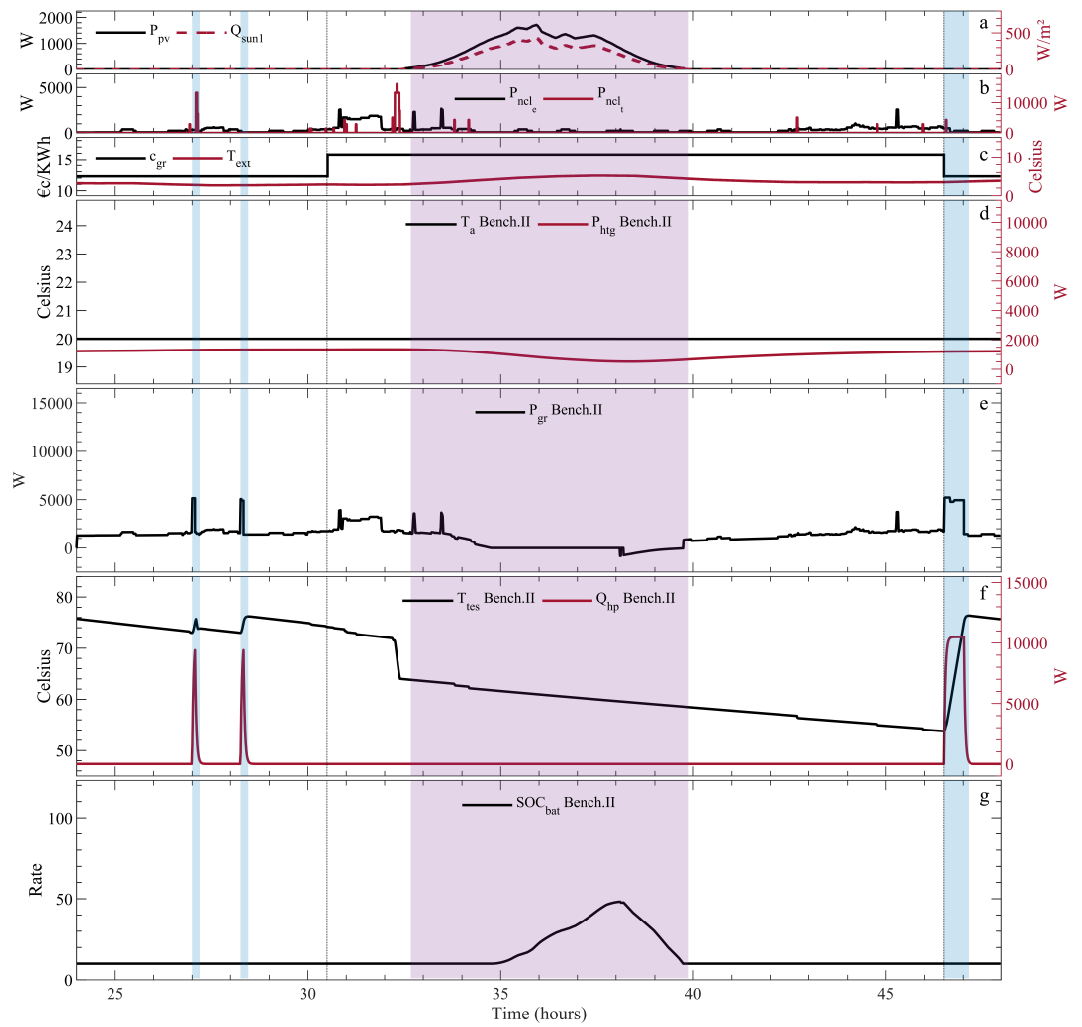

Figure 9: Simulation results with benchmark II. Figure 9.a depicts photovoltaic power $P_{p v}$ and sun heat $Q_{\text {sun } 1}$. Figure 9.b depicts non-controllable loads from electric carrier $P_{n c l}$ and thermal carrier $P_{n c l_{t}}$. Figure 9.c depicts grid cost $c_{g r}$ and outdoor temperature $T_{\text {ext }}$. Figure 9.d depicts indoor air temperature $T_{a}$ and building heating power $P_{h t g}$. Figure 9.e depicts grid power $P_{g r}$. Figure 9.f depicts thermal storage temperature $T_{t e s}$ and converter delivery heating $Q_{h p}$. Figure 9.g depicts battery stored energy as state of charge $S O C_{b a t}$.

no energy is available inside the battery, energy is imported from the grid (it started at $42.61 \mathrm{~h}$ ), figure 8.e.

This behaviour is in strict accordance with the Bench.I controller presented in section 4.8. Here, the lack of anticipation for Bench.I leads to request energy from the grid even when the tariff is higher. The benchmark I did not anticipate the energy cost variations.

Figure 9 depicts the results from the Bench.II. The first three plots depict input data, figures 9.a, 9.b and 9.c. Same behaviour as Bench.I is observed from the building temperature $T_{a}$ Bench.II, figure 9.d, and the thermal storage 


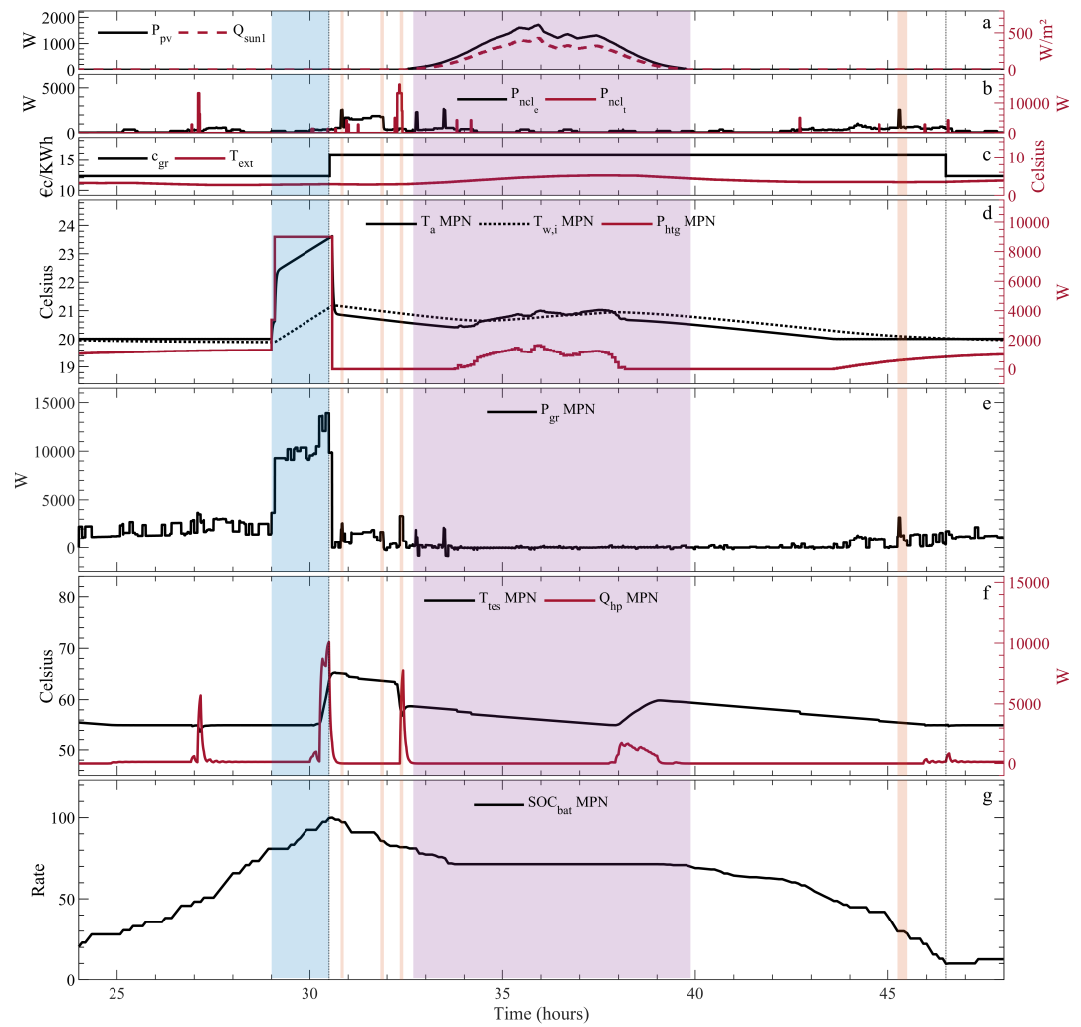

Figure 10: Simulation results with MPN. Figure 10.a depicts photovoltaic power $P_{p v}$ and sun heat $Q_{\text {sun } 1}$. Figure 10.b depicts non-controllable loads from electric carrier $P_{n c l}$ and thermal carrier $P_{n c l_{t}}$. Figure 10.c depicts grid cost $c_{g r}$ and outdoor temperature $T_{e x t}$. Figure 10.d depicts indoor air temperature $T_{a}$, wall temperature $T_{w, i}$ and building heating power $P_{h t g}$. Figure 10.e depicts grid power $P_{g r}$. Figure 10.f depicts thermal storage temperature $T_{t e s}$ and converter delivery heating $Q_{h p}$. Figure 10.g depicts battery stored energy as state of charge $S O C_{b a t}$.

temperature $T_{\text {tes }}$ Bench.II, figure 9.f. However, compared to Bench.I when the PV power is available, figure 9.a, highlighted in red filigree, the grid power, and the battery $S O C_{b a t}$ Bench.II, are not the same, figures 9.e, 9.g. The PV power is first used to power the loads rather than to charge the battery. This behaviour is in exact accordance with the Bench.II controller presented in section 4.8. Also, when the PV power is higher than the loads, the energy is used to charge the battery. Here, Bench.II did not anticipate the cost variation like Bench.I. However, compared to Bench.I, it reduced the exported energy to the grid and reduced battery usage. 
Figure 10 depicts the output results from the MPN introduced in this work. The first three plots depict input data, figures 10.a, 10.b and 10.c. From 28.9 to $30.5 \mathrm{~h}$, we can first observe a huge power consumption from the grid, $P_{g r} \mathrm{MPN}$, figure 10.e and blue filigree. $30.5 \mathrm{~h}$ is the end of the low tariff period. During this period, this consumption is over $9 \mathrm{~kW}$ (Fig. 10.d):

- Part of these power is dedicated to complete battery charging $S O C_{b a t}$ MPN, figure 10.g;

- $9 \mathrm{~kW}$ are dedicated to the heating system to overheat the air in the building that reaches $24^{\circ} \mathrm{C}$ while the set point is $20^{\circ} \mathrm{C}, P_{h t g}$ MPN, $T_{a} \mathrm{MPN}$, figure 10.d. Note that $9 \mathrm{~kW}$ is the maximum constraint of $P_{h t g}$ MPN, see table 3 ;

- TES was charged through the use of heat pump $Q_{h p}$ MPN, explaining the output power peak of $10 \mathrm{~kW}$ at the end of the low grid tariff, figure 10.f. The output power peak appeared just before the end of low grid tariff allowed to minimise TES heat loss and it reduces economic cost.

This behaviour of EMPC is due to prediction capabilities and 24 hours ahead of time horizon that leads to anticipate the grid tariff variations: when the grid tariff is low, EMPC stores energy to reduce energy consumption from the grid when the tariff is higher. In that view, EMPC controls the building temperature $T_{a}$ MPN and overheats the building. Then, heat is stored through thermal inertia of the walls when the grid tariff is low and is released during the rest of the day when the grid tariff is high. The idea to use building thermal inertia is usually employed in order to reduce heat cost [54]. Whereas, since Bench.I and Bench.II had not the prediction capabilities and they did not overheats the building.

Moreover, $T_{a}$ MPN decreased dramatically when $P_{h t g}$ MPN dropped to 0W, figure 10.d right after $30.5 \mathrm{~h}$. This drop has happened because the air inertia is smaller than the wall inertia. When the building air is overheated, the walls are heated by the surrounding air, but their temperature, $T_{w, i}$ MPN, increased moderately over $20^{\circ} \mathrm{C}$, figure 10.d. It remains colder than the air. When the heater stops, the heat flow is reversed that means the wall heats the air. This behaviour can be reduced by different heating system where $P_{h t g}$ is leaked to $T_{w, i}$, rather than connected to air node $T_{a}$, figure 6 .

Besides, we can observe that non-controllable loads $P_{n c l}$ achieved $2 \mathrm{~kW}$ sometimes, highlighted in yellow filigree, figure 10.b. At the same time, SOC of batteries $S O C_{b a t}$ is decreased, and small peaks in the power demand on the grid $P_{g r}$ MPN, figure 10.g, 10.e and yellow filigree. As a result, loads is powered both by the batteries and the grid. The resort to the grid is only due to the battery power limitation at $1.1 \mathrm{~kW}$ (table 3 ). On the contrary, in the case of Bench. I and II, only the grid provides power at these periods, since the battery is discharged. Here again, EMPC anticipated the resort to the battery by charging it when the tariff is low whereas the lack of anticipation for Bench. I and II leads to request the grid even when the tariff is higher. 
PV power $P_{p v}$ is not null from $32.68 \mathrm{~h}$ to $39.88 \mathrm{~h}$, highlighted in red filigree, figure 10.a. Two main events are visible:

- From $32.68 \mathrm{~h}$ to $33.58 \mathrm{~h}, \mathrm{PV}$ power is smaller than the loads power $P_{n c l}$ and the battery or the grid brought out additional power, figure 10.g and 10.e. As a result, $S O C_{b a t} \mathrm{MPN}$ is decreased, figure 10.g.

- From 33.58 to $39.88 \mathrm{~h}, \mathrm{PV}$ power is higher than the loads. Power is sent off in the heating system $P_{h t g}$ MPN, from $33.8 \mathrm{~h}$ to $38 \mathrm{~h}$, or in the heat pump $Q_{h p}$ MPN, figure 10.d and 10.f. In the meantime, the grid power $P_{g r}$ MPN remained null and battery $S O C_{b a t}$ MPN is not fully charged, figure 10.e and 10.g.

In MPN case, PV production is used to powered the non-controllable loads, overheating the building or heat the TES, instead of selling energy to the grid or storing it in the batteries in the way as Bench.I and Bench.II did. This behaviour reduces energy loss from battery charging and discharging and MPN allocates energy efficiently compared to benchmarks.

Finally, from $24 \mathrm{~h}$ to $30 \mathrm{~h}, T_{\text {tes }}$ MPN plateaued at the lower constraint, $55^{\circ} \mathrm{C}$ (table 3), figure 10.f. Moreover, from $30 \mathrm{~h}$ to $30.5 \mathrm{~h}$, thermal storage is heating up, but the thermal storage temperature from MPN didn't reach the maximum temperature $\left(75^{\circ} \mathrm{C}\right)$, figure 10 .f. $30.5 \mathrm{~h}$ is the end of the low tariff period. Furthermore, thermal loads $P_{n c l_{t}}$ (figure 10.b) are offset during the simulation, it is visible at $27 \mathrm{~h}, 32.42 \mathrm{~h}$ and $46.58 \mathrm{~h}$ with $Q_{h p}$ MPN greater than 0 during that time, figure 10.f. In MPN case, TES temperature is low in order to minimise heat loss and to reduce economic cost. The among of energy losses by TES for benchmarks and MPN during the simulation is shown in table 5 . This behaviour is due to prediction capabilities and 24 hours ahead of time horizon that leads to anticipate the TES loss, the PV power, the loads and the tariff variations.

\begin{tabular}{cccc}
\multicolumn{4}{c}{ Table 5: Energy losses by TES. } \\
\hline Case & Data & Gain & Percent \\
\hline Bench.I & $10.52 \mathrm{kWh}$ & - & - \\
Bench.II & $10.52 \mathrm{kWh}$ & 0 & 0 \\
MPN & $9.89 \mathrm{kWh}$ & $0.63 \mathrm{kWh}$ & $5.99 \%$ \\
\hline
\end{tabular}

Table 6 depicts economic results comparison for simulations, MPN and benchmarks. It shows that MPN has the lowest economic cost by the price of $€ 4.104$, meanwhile Bench. I has the highest cost for this winter day scenario with $€ 4.471$. MPN and EMPC reduced cost by $8.21 \%$ compared to Bench. I. Then, tables 6 depicts grid energy swap from MPN and benchmarks. MPN extracted more energy than benchmarks with $32.09 \mathrm{~kW}$ h. Furthermore, the lowest amount of energy extracted from the grid is achieved by Bench. II with $31.37 \mathrm{~kW}$ h. In addition, it can be seen from table 6 that Bench. I has injected to the grid more energy than MPN and Bench. II with $0.6014 \mathrm{~kW} \mathrm{~h}$. Finally, the lowest amount of energy injected to the grid is achieved by MPN with 
Table 6: Winter scenario results.

\begin{tabular}{cccc}
\hline & Balance sheet & Gain & Percent \\
\hline Benchmark I & $€ 4.471$ & - & - \\
Benchmark II & $€ 4.402$ & $€ 0.069$ & $1.54 \%$ \\
MPN & $€ 4.104$ & $€ 0.367$ & $8.21 \%$ \\
\hline & Energy imported & Gain & Percent \\
\hline Benchmark I & $31.88 \mathrm{kWh}$ & - & - \\
Benchmark II & $31.37 \mathrm{kWh}$ & $0.22 \mathrm{kWh}$ & $0.7 \%$ \\
MPN & $32.09 \mathrm{kWh}$ & $-0.04 \mathrm{kWh}$ & $-0.12 \%$ \\
\hline & Energy injected & Gain & Percent \\
\hline Benchmark I & $0.6014 \mathrm{kWh}$ & - & - \\
Benchmark II & $0.4872 \mathrm{kWh}$ & $0.1142 \mathrm{kWh}$ & $18.99 \%$ \\
MPN & $0.2532 \mathrm{kWh}$ & $0.3482 \mathrm{kWh}$ & $57.9 \%$ \\
\hline \multicolumn{5}{c}{ Self-consumption } & Self-production \\
\hline Benchmark I & $93.07 \%$ & $13.03 \%$ \\
Benchmark II & $94.38 \%$ & $14.41 \%$ & \\
MPN & $97.08 \%$ & $14.4 \%$ & \\
\hline \multicolumn{4}{c}{} \\
\hline
\end{tabular}

$0.2532 \mathrm{~kW} \mathrm{~h}$. This result is counter-intuitive, because MPN has reduced income from selling energy to the grid. However the overall cost is reduced. This result is explained by self-consumption and self-production rates. They are calculated based on:

$$
\begin{aligned}
\text { Self-consumption } & =100 \times \frac{\text { Energy produced }- \text { Energy injected }}{\text { Energy produced }} \\
\text { Self-production } & =100 \times \frac{\text { Energy consumed }- \text { Energy imported }}{\text { Energy consumed }}
\end{aligned}
$$

According to self-consumption, Bench. I has the lowest self-consumption index with $93.07 \%$ and MPN has the highest self-consumption index with $97.08 \%$. According to self-production index, Bench. I has the lowest index with $13.03 \%$ and Bench. II has the highest index with $14.41 \%$. However Bench. II is followed closely by MPN with $14.4 \%$. MPN and EMPC have capability to conjointly increase self-production and self-consumption, while keeping economic performance optimised. When self-production and self-consumption are increased, dependence from grid is reduced and energy is consumed close to energy generators.

Table 7 depicts results from the second scenario. This scenario is directly related to a summer day with more solar production and less consumption than winter day. It can be seen that the MPN solution provides the lowest economic cost with $€ 0.049$ compared to benchmarks. Both the imported and injected energies are reduced using the MPN solution with the lowest amount of imported energy $(3.568 \mathrm{~kW} \mathrm{~h})$ and the lowest amount of injected energy $(4.455 \mathrm{~kW} \mathrm{~h})$. Furthermore, it increases self-consumption up to $86.35 \%$ and self-production $67.29 \%$ compared to benchmarks. These results are consistent with the winter scenario, 
the MPN (using EMPC) having capability to reduce dependency from grid.

Table 7: Summer scenario results

\begin{tabular}{cccc}
\multicolumn{4}{c}{ Table 7: Summer scenario results. } \\
\hline & Balance sheet & Gain & Percent \\
\hline Benchmark I & $€ 0.3111$ & - & - \\
Benchmark II & $€ 0.074$ & $€ 0.2371$ & $76.21 \%$ \\
MPN & $€ 0.049$ & $€ 0.2621$ & $84.24 \%$ \\
\hline & Energy imported & Gain & Percent \\
\hline Benchmark I & $7.057 \mathrm{kWh}$ & - & - \\
Benchmark II & $4.372 \mathrm{kWh}$ & $2.685 \mathrm{kWh}$ & $38.05 \%$ \\
MPN & $3.568 \mathrm{kWh}$ & $3.489 \mathrm{kWh}$ & $49.44 \%$ \\
\hline \multicolumn{5}{c}{ Energy injected } & Gain & Percent \\
\hline Benchmark I & $6.812 \mathrm{kWh}$ & - & - \\
Benchmark II & $5.11 \mathrm{kWh}$ & $1.702 \mathrm{kWh}$ & $33.30 \%$ \\
MPN & $4.455 \mathrm{kWh}$ & $2.357 \mathrm{kWh}$ & $34.6 \%$ \\
\hline \multicolumn{5}{c}{ Self-consumption } & Self-production \\
\hline Benchmark I & $79.57 \%$ & $37.44 \%$ \\
Benchmark II & $84.68 \%$ & $61.63 \%$ & \\
MPN & $86.35 \%$ & $67.29 \%$ & \\
\hline \multicolumn{4}{c}{}
\end{tabular}

\section{Conclusion}

A MPN based solution was proposed in this work to cope with drawbacks from prosumer node and EH. The case study dealt with MES made of electric and thermal carriers. Carriers coupling was done through a heat pump converting electricity in to thermal energy. Moreover, electric carrier had grid connection while thermal carrier did not. The proposed MPN and simulation resultshave shown that:

- MPN is able to model MES dynamics and multiple energy carriers are considered;

- MPN is able to model MES without using conversion factors for energy carriers. The conversion relies on devices models;

- MES dynamics bring variable coupling between energy carriers and may support satisfactorily minute scaled optimisation;

- The proposed methodology conveniently applies to MES models based on two energy carriers, to be controlled by EMPC;

- MPN can deal with on-grid and off-grid connection, and power flow is bidirectional from MPN to grid or grid to MPN.

In order to assess MPN performance, two benchmarks have been proposed to be compared to MPN with EMPC. In terms of economic performance, it 
is observed that in the simulation scenario, MPN with EMPC decreased economic cost compared to the benchmarks, with a cost cut of $8.21 \%$ compared to benchmark I. Cost decrease has been performed thanks to:

- EMPC performs optimisation whilst prediction from disturbances (loads, photovoltaic power, temperature) are taken into account;

- The proposed MPN deals with system dynamic whilst different energy carriers are taken into account with state-space model and power balance;

Concerning self-producer index, MPN has gained the best rates compared to benchmarks I and II. In terms of energy imported, MPN imported more energy to the grid compared to benchmarks, however, this is balanced out with less energy injected to the grid by the MPN compared to benchmarks. These results show that better economic results can be achieved with more imported energy compared to benchmarks.

However, some opened issues still remain. The present work has some limitations as it relies on models' assumptions. Indeed, it uses power balance and energy approach; this brings restrictions because the electric carrier could be more precisely described in terms of current and voltage, and the thermal carrier, in terms of mass flow, temperature and pressure. Secondly, the approach is limited to minute scale energy flow optimisation and is not suited for second scale control systems (less than minute scale) because of the power balance and energy approach. Third, energy devices like a heat pump, battery, thermal storage, thermal building are highly non-linear. In this study, linear first-order models were used to model them. Future works will focus on physical MES' modelling together with the MPN framework in order to overcome power modelling limitations. In addition, model uncertainties and suitable EMPC algorithm should be studied to handle uncertainties in the MPN framework. Also, hierarchical control should be investigated with aiming to get a regulatory control and multi-time scale optimisation.

\section{Acknowledgment}

The work was supported by Conseil Régional des Pays de la Loire. The authors would like to sincerely thank Xavier Faure for his expertise about building modeling, Mathieu Vallée for comments that improved the manuscript, and finally the anonymous reviewers for their insights and remarks.

\section{References}

[1] Lamnabhi-Lagarrigue, F., Annaswamy, A., Engell, S, et al.: 'Systems \& Control for the future of humanity, research agenda: Current and future roles, impact and grand challenges', Annual Reviews in Control, 2017, 43, pp. $1-64,10.1016 /$ j.arcontrol.2017.04.001 
[2] Mancarella, P.: 'MES (multi-energy systems): An overview of concepts and evaluation models', Energy, 2014, 65, pp. 1-17, 10.1016/j.energy.2013.10.041

[3] Jørgensen, J., B., Sokoler, L., E., Standardi, L., et al.: 'Economic MPC for a linear stochastic system of energy units', Proc. European Control Conference (ECC), Aalborg, Denmark, Jully 2016, pp. 903-909, 10.1109/ECC.2016.7810404

[4] Pereira, M., Muñoz de la Peña D., Limon, D.: 'Robust economic model predictive control of a community micro-grid', Renewable Energy, 2017, 100, pp. 3-17, 10.1016/j.renene.2016.04.086

[5] Liberati, F., Di Giorgio, A.: 'Economic Model Predictive and Feedback Control of a Smart Grid Prosumer Node', Energies, 2018, 11, (1), 48, 10.3390/en11010048

[6] Báez-González, P., Real del, A. J., Ridao Carlini, M., A., et al.: 'Dayahead economic optimization of energy use in an olive mill', Control Engineering Practice, 2016, 54, pp. 91-103, 10.1016/j.conengprac.2016.05.019

[7] Baños, R., Manzano-Agugliaro, F., Montoya, F.G., Gil, C., Alcayde, A., Gómez, J.: 'Optimization methods applied to renewable and sustainable energy: A review', Renewable and Sustainable Energy Reviews, 2011, 15, (4), pp. 1753-1766, 10.1016/j.rser.2010.12.008

[8] Mohammadi, M., Noorollahi, Y., Mohammadi-Ivatloo, B., et al.: 'Optimal Scheduling of Energy Hubs in the Presence of Uncertainty-A Review', Journal of Energy Management and Technology, 2017, 1, (1), pp. 1-17, $10.22109 /$ jemt.2017.49432

[9] Evins, R., Orehounig, K., Dorer, V., Carmeliet, J.: 'New formulations of the 'energy hub' model to address operational constraints', 2014, Energy, 73, pp. 387-398, 10.1016/j.energy.2014.06.029

[10] Labidi, M., Eynard, J., Faugeroux, O., Grieu, S.: 'A new strategy based on power demand forecasting to the management of multi-energy district boilers equipped with hot water tanks', 2017, Applied Thermal Engineering, 113, pp. 1366-1380, 10.1016/j.applthermaleng.2016.11.151

[11] Li, B., Roche, R., Paire, D., Miraoui, A.: 'Coordinated scheduling of a gas/electricity/heat supply network considering temporal-spatial electric vehicle demands', Electric Power Systems Research, 2018, 163, (A), pp. $382-395,10.1016 /$ j.epsr.2018.07.014

[12] Shi, H., Blaauwbroek, N., Nguyen, P., H., Kamphuis, R., I., G.: 'Energy management in Multi-Commodity Smart Energy Systems with a greedy approach', 2016, Applied Energy, 167, pp. 385-396, 10.1016/j.apenergy.2015.11.101 
[13] Bigdeli, N.: 'Optimal management of hybrid PV/fuel cell/battery power system: A comparison of optimal hybrid approaches', Renewable and Sustainable Energy Reviews, 2015, 42, pp. 377-393, $10.1016 /$ j.rser.2014.10.032

[14] Real del, A., J., Arce, A., Bordons, C.: 'Combined environmental and economic dispatch of smart grids using distributed model predictive control', International Journal of Electrical Power \& Energy Systems, 2014, 54, pp. 65-76, 10.1016/j.ijepes.2013.06.035

[15] Parisio, A., Del Vecchio, C., Vaccaro, A., 'A robust optimization approach to energy hub management', International Journal of Electrical Power \& Energy Systems, 2012, 42, (1), pp. 98-104, 10.1016/j.ijepes.2012.03.015

[16] Fauvel, C., Claveau, F., Chevrel, P., Fiani, P.: 'A flexible design methodology to solve energy management problems', International Journal of Electrical Power \& Energy Systems, 2018, 97, pp. 220-232, 10.1016/j.ijepes.2017.11.005

[17] Ellis, M., Durand, H., Christofides, P., D.: 'A tutorial review of economic model predictive control methods', Journal of Process Control, 2014, 24, (8), pp. 1156-1178, 10.1016/j.jprocont.2014.03.010

[18] Rawlings, J., B., Angeli, D., Bates, C., N.: 'Fundamentals of economic model predictive control', Proc. 51st IEEE Conference on Decision and Control (CDC), Maui, HI, USA, December 2012, pp. 3851-3861, 10.1109/CDC.2012.6425822

[19] Ellis, M., Liu, J., Christofides, P., D.: 'Economic Model Predictive Control: Theory, Formulations and Chemical Process Applications', (Springer, Cham, 2017), 10.1007/978-3-319-41108-8

[20] Ruelens, F., Claessens, B. J., Quaiyum, S., De Schutter, B., Babuška R., Belmans,R.: 'Reinforcement Learning Applied to an Electric Water Heater: From Theory to Practice',IEEE Transactions on Smart Grid, 2018, 9, (4), pp. 3792-3800, 10.1109/TSG.2016.2640184

[21] Arnold M., Negenborn R.R., Andersson G., De Schutter B.: 'Distributed Predictive Control for Energy Hub Coordination in Coupled Electricity and Gas Networks'. In: Negenborn R., Lukszo Z., Hellendoorn H. (Ed.): 'Intelligent Infrastructures. Intelligent Systems, Control and Automation: Science and Engineering' (Springer, Dordrecht, 2011, vol 42.), pp. 235273, 10.1007/978-90-481-3598-1_10

[22] Nassourou, M., Puig, V., Blesa, J.: 'Robust Optimization based Energy Dispatch in Smart Grids Considering Simultaneously Multiple Uncertainties: Load Demands and Energy Prices', Proc. 20th IFAC World Congress, Toulouse, France, July 2017, pp. 6755-6760, 10.1016/j.ifacol.2017.08.1175 
[23] Nassourou, M., Blesa, J., Puig, V.: 'Optimal energy dispatch in a smart micro-grid system using economic model predictive control', Proceedings of the Institution of Mechanical Engineers, Part I: Journal of Systems and Control Engineering, Prepublished July 2018, 10.1177/0959651818786376

[24] Real del, A., J., Arce, A., Bordons, C.: 'An Integrated Framework for Distributed Model Predictive Control of Large-Scale Power Networks', IEEE Transactions on Industrial Informatics, 2014, 10, (1), pp. 197-209, 10.1109/TII.2013.2273877

[25] Ayele, G., T., Haurant, P., Laumert, B., Lacarrière, B.: 'An extended energy hub approach for load flow analysis of highly coupled district energy networks: Illustration with electricity and heating', Applied Energy, 2018, 212, pp. 850-867, 10.1016/j.apenergy.2017.12.090

[26] Caianiello, P., Costantini, S., De Gasperis, G., et al.: 'Application of Hybrid Agents to Smart Energy Management of a Prosumer Node', in Omatu, S., Neves, J., Rodriguez, J., Paz Santana, J., Gonzalez, S. (Ed.): 'Distributed Computing and Artificial Intelligence. Advances in Intelligent Systems and Computing' (Springer, Cham, 2013, vol. 217), 10.1007/9783-319-00551-5_71

[27] Cuadra, L., Pino del, M., Nieto-Borge, J., et al.: 'Optimizing the Structure of Distribution Smart Grids with Renewable Generation against Abnormal Conditions: A Complex Networks Approach with Evolutionary Algorithms', Energies, 2017, 10, (8), 1097, 10.3390/en10081097

[28] Long, S., Parisio, A., Marjanovic, O., 'A conversion model for nodes in multi-energy systems' ,IEEE Manchester PowerTech, Manchester, UK, June 2017, pp. 1-6, 10.1109/PTC.2017.7981052

[29] Geidl M., Koeppel G., Favre-Perrod, P., et al.: 'Energy hubs for the future', IEEE Power and Energy Magazine, 2007, 5, (1), pp. 24-30, 10.1109/MPAE.2007.264850

[30] Mohammadi, M., Noorollahi, Y., Mohammadi-ivatloo, B., Yousefi, H.: 'Energy hub: From a model to a concept - A review', Renewable and Sustainable Energy Reviews, 2017, 80,pp. 1512-1527, 10.1016/j.rser.2017.07.030

[31] Hepbasli, A., Kalinci, Y.: 'A review of heat pump water heating systems', Renewable and Sustainable Energy Reviews, 2009, 13, (6-7), pp. 1211$1229,10.1016 /$ j.rser.2008.08.002

[32] MacArthur, J., W.: 'Transient heat pump behaviour: a theoretical investigation', International Journal of Refrigeration, 1984, 7, (2), pp. 123-132, 10.1016/0140-7007(84)90025-2 
[33] Vargas, J., V., C., Parise, J., A., R.: 'Simulation in transient regime of a heat pump with closed-loop and on-off control', International Journal of Refrigeration, 1995, 18, (4), pp. 235-243, 10.1016/0140-7007(95)96862-Z

[34] Arteconi, A., Hewitt, N., J., Polonara, F.: 'Domestic demand-side management (DSM): Role of heat pumps and thermal energy storage (TES) systems', Applied Thermal Engineering, 2013, 51, (1-2), pp. 155-165, 10.1016/j.applthermaleng.2012.09.023

[35] Kramer, M., Jambagi, A., Cheng, V.: 'A model predictive control approach for demand side management of residential power to heat technologies', IEEE International Energy Conference (ENERGYCON), Leuven, Belgium, April 2016, pp. 1-6, 10.1109/ENERGYCON.2016.7513903

[36] Zong, Y., Böning, G., M., Santos, R., M., et al.: 'Challenges of implementing economic model predictive control strategy for buildings interacting with smart energy systems', Applied Thermal Engineering, 2017, 114, pp. 1476-1486, 10.1016/j.applthermaleng.2016.11.141

[37] Andrić, I., Gomes, N., Pina, A., Ferrão, P., Fournier, J., Lacarrière, B., Le Corre, O.: 'Modeling the long-term effect of climate change on building heat demand: Case study on a district level', Energy and Buildings, 2016, 126, pp. 77-93, 10.1016/j.enbuild.2016.04.082

[38] Tremblay, O., Dessaint, L., A., Dekkiche, A., I.: 'A Generic Battery Model for the Dynamic Simulation of Hybrid Electric Vehicles', Proc. IEEE Vehicle Power and Propulsion Conference, Arlington, TX, USA, 2007, pp. 284289, 10.1109/VPPC.2007.4544139

[39] MATLAB and Simscape Toolbox Release 2018a, The MathWorks, Inc., Natick, Massachusetts, United States

[40] Löfberg, J.: 'YALMIP : a toolbox for modeling and optimization in MATLAB', Proc. IEEE International Symposium on Computer Aided Control Systems Design, Taipei, Taiwan, September, 2004, pp. 284-289, 10.1109/CACSD.2004.1393890

[41] Lougee-Heimer, R.: 'The Common Optimization INterface for Operations Research: Promoting open-source software in the operations research community', IBM Journal of Research and Development, 2003, 45, (1), pp. 57$66,10.1147 /$ rd. 471.0057

[42] Knudsen, M., D., Petersen, S.: 'Model predictive control for demand response of domestic hot water preparation in ultra-low temperature district heating systems', Energy and Buildings, 2017, 146, pp. 55-64, 10.1016/j.enbuild.2017.04.023

[43] 'LG chem RESU 3.3', https://www.sharp.co.uk/cps/rde/xchg/gb/hs.xsl//html/product-details-batterie-solutions-2219.htm?product=LGCHEMRESU33, accessed August 2018 
[44] 'Tarif Bleu EDF', https://particulier.edf.fr/fr/accueil/offres/electricite/tarifbleu/option-heures-creuses.html, accessed August 2018

[45] Boßmann, T., Eser, E., J.: 'Model-based assessment of demand-response measures-A comprehensive literature review', Renewable and Sustainable Energy Reviews, 2016, 57, pp. 1637-1656, 10.1016/j.rser.2015.12.031

[46] Shariatzadeh, F., Mandal P., Srivastava A., K.: 'Demand response for sustainable energy systems: A review, application and implementation strategy', Renewable and Sustainable Energy Reviews, 2015, 45, pp. 343350, 10.1016/j.rser.2015.01.062

[47] Paterakis, N., G., Erdinç, O., Catalão, J., P., S.: 'An overview of Demand Response: Key-elements and international experience', Renewable and Sustainable Energy Reviews, 2017, 69, pp. 871-891, $10.1016 /$ j.rser.2016.11.167

[48] 'Arrêté du 9 mai 2017 fixant les conditions d'achat de l'électricité produite par les installations implantées sur bâtiment utilisant l'énergie solaire photovoltaïque, d'une puissance crête installée inférieure ou égale à 100 kilowatts telles que visées au $3^{\circ}$ de l'article D. 31415 du code de l'énergie et situées en métropole continentale ', https://www.legifrance.gouv.fr/eli/arrete/2017/5/9/DEVR1712972A/jo/texte accessed August 2018

[49] Young, L., Meiry, J.: 'Bang-bang aspects of manual control in highorder systems', IEEE Transactions on Automatic Control, 1965, 10, (3), pp. 336-341, 10.1109/TAC.1965.1098168

[50] 'storelio advanced energy systems', http://www.storelio.com/eng, accessed April 2019

[51] 'Billy Home Energy Storage system', http://www.technideal.com/autoconsommation-2, accessed April 2019

[52] McKenna, E., Thomson, M.: 'High-resolution stochastic integrated thermal-electrical domestic demand model', Applied Energy, 2016, 165, pp. $445-461,10.1016 / \mathrm{j}$.apenergy.2015.12.089

[53] 'solar radiation data', http://www.soda-pro.com/fr/webservices/radiation/helioclim-3-archives-for-free, accessed February 2019

[54] Dominković, D., F., Gianniou, P., Münster, M., Heller, A., Rode, C.: 'Utilizing thermal building mass for storage in district heating systems: Combined building level simulations and system level optimization', Energy, 2018, 153, pp. 949-966, 10.1016/j.energy.2018.04.093 
[55] Touretzky, C., R., Baldea M.:'Integrating scheduling and control for economic MPC of buildings with energy storage', Journal of Process Control, 2014, 24, (8), pp. 1292-1300, 10.1016/j.jprocont.2014.04.015

[56] Rawlings, J. B., Patel, N. R., Risbeck, M. J., Maravelias, C. T., Wenzel, M. J., Turney, R. D.: 'Economic MPC and real-time decision making with application to large-scale HVAC energy systems', Computers \& Chemical Engineering, 2018, 114, pp. 89-98, 10.1016/j.compchemeng.2017.10.038

[57] Alanqar, A., Durand, H., Albalawi, F., Christofides, P. D.:'An economic model predictive control approach to integrated production management and process operation', AIChE Journal, 2017, 63, (6), pp. 1892-1906, 10.1002/aic. 15553

[58] Copp, D. A., Hespanha, J. P.:'Simultaneous nonlinear model predictive control and state estimation'. Automatica, 2017, 77, pp. 143-154, 10.1016/j.automatica.2016.11.041

[59] Heidarinejad, M., Liu, J., Christofides, P. D.:'State-estimation-based economic model predictive control of nonlinear systems', Systems \& Control Letters, 2012, 61, (9), pp. 926-935, 10.1016/j.sysconle.2012.06.007 